\title{
Substitution Effects in Parental Investments
}

\author{
Loren Brandt, Aloysius Siow, and Hui Wang* \\ Department of Economics \\ University of Toronto \\ This draft: May, 2009 \\ Preliminary. Please do not cite.
}

\begin{abstract}
The paper provides causal estimates of how parents adjust bride prices to compensate sons for differences in schooling investments in rural China. The benchmark estimate imply that when a son receives one yuan less in schooling investment than his brother, he will obtain 0.4 yuan more in his marital transfers as partial compensation. Accounting for measurement error in schooling expenditure, discounting of the timing of school expenditures and bride prices, heterogeneous returns to schooling, partial appropriation of schooling returns by children, or public goods' components in children's consumption do not change the causal estimate. Although the standard income transfer derivative test of the unitary model is rejected, the assumptions necessary for the test are unlikely to be valid. The paper provides an alternative sequential income transfer test based on observing two transfers per child. This test supports the unitary model.
\end{abstract}

\section{Introduction}

Parents have to decide how much to invest and how to invest in each of their children. In a series of classic papers summarized in Becker 1991, Becker argues that parents should first choose investments in their children to maximize total household wealth. Then parents should use intra-household transfers to distribute consumption among their children to maximize parental utility. Assuming inelastic labor supplies, family members' consumption levels are independent of their income contributions to the family wealth. ${ }^{1}$

The above model is known as the unitary model of the family. Tests of the model based on the above prediction is known as the income transfer difference test (Cox 1987): If family member $i$ gains one dollar of exogenous own income

\footnotetext{
*We thank ... Correspondence: Loren Brandt, Email: brandt@chass.utoronto.ca, Aloysius 'Siow Email: siow@chass.utoronto.ca. Hui Wang, Email: jackie.wang@utoronto.ca.

${ }^{1}$ Consumption and labor supplies are correlated when the marginal utlities of consumption and labor supply are not separable (Rosenzweig et. al.)
} 
and another member $j$ loses one dollar of exogenous own income, then $i$ will receive one dollar less intrahousehold transfer and $j$ will receive one dollar more transfer; hence every family member's consumption is kept the same.

Using primarily data from the United States, researchers have studied the above implications for parental transfers when their children's incomes differ exogenously. Menchik $(1980,1988)$ find that bequests are generally divided equally among siblings. Cox (1987) and Cox and Rank (1992) find that children's incomes are positively correlated with inter-vivos parental transfers. Altonji et al (1997) estimate that parental transfers decrease by 13 cents when a parent loses one dollar and a child gains a dollar. These findings largely cast doubt on the unitary model. Using Indonesian data, Raut and Tran (2005) find more support for the unitary model.

In some circumstances, the optimal transfer to a child may be negative and infeasible because the child refuses to cooperate. In these cases, optimal parental investments are more complicated because the two-step optimization breaks down (Behrman, et. al. (1995)). When negative transfers are infeasible, tests using data with only positive transfers may suffer from selection bias. Cox (1987) use the Heckit estimator to correct for sample selection. Altonji et al (1997) used a more behaviorally grounded alternative selection correction estimator. Raut and Tran (2005) also use different selection correction estimators.

Becker's model is static. Most empirical work have tested the model with partial lifetime transfers and partial lifetime incomes which in general is inappropriate. $^{2}$ In some contexts, such tests remain valid (Altonji et al 1997).

Due to data limitations, most researchers also do not control for household unobservables. Together with partial measures of lifetime transfers and incomes, inference without controlling for household unobservables should be regarded as provisionary. Using data on siblings and family fixed effects, McGarry and Schoeni (1995), McGarry (1999), and Haider and McGarry (2006) find that children in the high earning categories receive significantly less parental transfers, providing some support for the unitary model.

Our paper builds on and extends the above literature. Instead of taking children's incomes as exogenous, we study how parents invest in their children's education and redistribute incomes due to these investments. Our unitary model delivers a family fixed effect regression of a measure of parental transfers on a measure of parental investment to children in the household. The analytic framework allows for concerns on different timing of parental investments and transfers, heterogeneous returns to investments, partial appropriation by the family of investment returns, public good nature of children's consumption, and other measures of parental transfers affecting the regression equation.

Our estimates provide a causal estimate of how parents adjust a particular transfer to their children in response to differences in a particular parent investment in these children. In general, there is no unambiguous structural

\footnotetext{
${ }^{2}$ For example, a child's unemployment spell may spill over two years. A parent may aid the child when the child's savings run low. Thus there may little or no transfer in the first year in which the unemployment spell is located. In the second year, the transfer may be high relative to the income loss. Such measurement error may lead to rejection of the unitary
} 
interpretation of this causal estimate. While our model admits a strong income transfer derivative test as in the earlier literature above, the restriction necessary for such an interpretation is unlikely to be valid in our context which is a traditional agricultural society. Thus researchers using standard income transfer derivative tests in a developing country context need to be sensitive to it applicability.

We estimate the model using a unique household survey dataset from rural China. This environment has several features which makes the unitary model more appropriate. Patrilocality is common. Most sons either live with their parents or stay in the same village after they marry. Parents and children often farm and do other businesses together. Thus there is more parental and adult child interaction, including income pooling, than in modern urban environments.

We focus on a significant investment and transfer made by Chinese villagers to their sons: educational expenditure and marital transfers (bride-price) respectively. In general, educational expenditure is the largest component of monetary parental investment. The bride-price is often the largest one time transfer from parents to sons. In this sense, they are closer to the lifetime inter-vivos transfer in Becker's model. While we use the term bride-price for convenience, most if not all the transfer is given to the son to help him setup of his new household. That is, it is not a transfer payment to the bride's family.

The baseline household fixed effects regression of marital transfers on schooling expenditure delivers an estimated coefficient of -0.4. The estimate imply that when a son receives one yuan less in schooling investment than his brother, he will obtain 0.4 yuan more in his marital transfers as partial compensation. The estimated coefficient is statistically different from -1.0. If a son retains all pecuniary return to his schooling, then the unitary model would imply that the coefficient should be smaller -1.0, In the farming households considered here, such a full appropriation assumption is very strong and thus the -1.0 benchmark is not compelling.

By adding post-marital land transfers to the bride price, we raise the absolute value of the estimated compensation coefficient to 0.6. Thus, accounting for other intra-household transfers substantially changes the estimate of how much parents compensate children for differences in parental investments. This finding cast reservations on existing income transfer difference tests which are based on partial observations of lifetime intrahousehold transfers, parental and children's incomes. On the other hand, with observations on multiple transfers, we show that the above sequential income transfer difference test provides an alternative test of the unitary model.

Our estimates also suggest that parents do not equalize consumption across children. For example, sons who live with their parents after marriage receive higher consumption. Accounting for heterogenous consumption allocations does not change our estimate of the compensation coefficient.

Accounting for measurement error in schooling expenditure, discounting of the timing of school expenditures and bride prices, heterogeneous returns to schooling, partial appropriation of schooling returns by children, or public goods' components in children's consumption do not explain the observed partial com- 
pensation.

Finally, functional form matters. Our behavioral model generates a linear regression model with multiplicative family fixed effects and not log linear or linear family fixed effects regression models.

Our current framework cannot deal with corner solutions in our measure of parental transfers where the two step optimization fails. This problem is not empirically relevant because nearly all of the sons receive strictly positive bride-prices. ${ }^{3,4}$

This paper is organized as follows. Section 2 presents a model of parental investment, derives testable implications, and discusses identification issues. Section 3 introduces the data and descriptive results. Section 4 reports the estimation results. Section 5 concludes the paper.

\section{A Unitary Model of Parental Investment}

Consider a household $h$ with two of their children, denoted by $i=1,2$ respectively. The parents have a wealth endowment of $m_{h}$. Child $i$ have ability level $a_{i h}$. The parents decide how to allocate family resources to its members.

Let the parents' utility function be

$$
U_{h}=u\left(c_{h}, c_{1 h}, c_{2 h}\right)
$$

where $u(\cdot)$ is a twice differentiable, concave function; $c_{h}$ represents for the consumption of the parents; $c_{i h}$ is child $i$ 's consumption. ${ }^{5}$ Family may have more

\footnotetext{
${ }^{3}$ It is an issue with dowries for daughters where one-third of the households give a zero dowry to at least one daughter.

${ }^{4}$ Our paper does not address gender difference. The gender difference patterns in our data are similar with other developing counties (e.g. villages examined by Quisumbing's (1994) in Philippines): girls receive comparable schooling investments with their brothers, but they generally receive significantly less dowry and nearly no bequests. We believe that this transfer disparity in gender requires deeper investigation of institutional details, which will not be captured by the simple generic Becker model. We leave this to future research.

${ }^{5}$ As later on we will use the marital transfer as a measure of inter-vivos transfers, we might think of incorporating the marital market clearing conditions into our framework. This can be easily done by assuming positive assortative matching among spouses. Imagine that parents care not only about the consumption level of their own children, but also about the consumption of whom they are married. For example, we can consider a family $h$ thinking of finding potential spouses for their sons 1 and 2 by equipping them with consumption level $c_{1 h}^{g}$ and $c_{2 h}^{g}$ so that they can attract brides with expected consumption levels of $\widehat{c}_{1 h}^{b}$ and $\widehat{c}_{2 h}^{b}$ respectively. Here we use superscript $g$ and $b$ to denote the groom and bride. The parental utility function is then $\widetilde{u}\left(c_{h}, c_{1 h}^{g}, \widehat{c}_{1 h}^{b}, c_{2 h}^{g}, \widehat{c}_{2 h}^{b}\right)$.

This equation, however, can be simplified to equation (1) through positive assortative matching in the marriage market. To illustrate this point, assume that the matching function takes the form $c_{i h}^{b}=\phi_{0}+\phi_{1} c_{i h}^{g}+\nu_{i h}$, where $i=1,2$ and $\nu_{i h}$ is the deviation (with zero mean) from positive assortative matching in wealth due to love and other matchspecific factors. From the parents' point of view, the expected daughter-in-law should possess $\widehat{c}_{i h}^{b}=\phi_{0}+\phi_{1} c_{i h}^{g}$. Plugging into the utility function yields $\widetilde{u}\left(c_{h}, c_{1 h}^{g}, \widehat{c}_{1 h}^{b}, w_{2 h}^{g}, \widehat{w}_{2 h}^{b}\right)=$ $\widetilde{u}\left(c_{h}, c_{1 h}^{g}, \phi_{0}+\phi_{1} c_{1 h}^{g}, c_{2 h}^{g}, \phi_{0}+\phi_{1} c_{2 h}^{g}\right)=u\left(c_{h}, c_{1 h}^{g}, c_{2 h}^{g}\right)$ which is the utility function (1) we use in the model.
} 
than two children; the consumption of other children in the household is subsumed in parental consumption.

Parents can invest their children's schooling. Let the parents spend $s_{i h}$ on child $i$,'s schooling. This expenditure generates $R\left(s_{i h}, a_{i h}\right)$ revenue from $i$,'s schooling for the family. $R($.$) may be labor earnings if the child works outside$ the home. In rural households, $R($.$) is the contribution of the child to family$ income. We expect $R($.$) to be increasing in its arguments.$

The total cost of $s_{i h}$ to the family is $C\left(s_{i h}, a_{1 h}, a_{2 h}, m_{h}\right)$. The cost function $C(\cdot)$ contains both the monetary and time cost to the family associated with each yuan spent in schooling. These costs include the shadow interest rate that family faces and the opportunity cost of the time that parents spend on supervising their children's study. In addition to $s_{i h}, m_{i h}$, and $a_{i h}$ affecting $C($.), we also allow $C($.$) to depend on the other sibling's attribute as well.$

The budget constraint of the family is

$$
\begin{aligned}
c_{h}+c_{1 h}+c_{2 h} & =m_{h}+\sum_{i=1}^{2}\left(R\left(s_{i h}, a_{i h}\right)-C\left(s_{i h}, a_{1 h}, a_{2 h}, m_{h}\right)\right) \\
& =m_{h}+\sum_{i=1}^{2} \Pi\left(s_{i h}, a_{1 h}, a_{2 h}, m_{h}\right) \\
& \equiv w_{h}
\end{aligned}
$$

where $\Pi(\cdot)$ denotes the profit from schooling investment and $w_{h}$ denotes the total family wealth available for consumption.

To maximize utility, schooling investments should be chosen to maximize total family wealth. The first order condition

$$
\frac{\partial R\left(s_{i h}, a_{i h}\right)}{\partial s_{i h}}=\frac{\partial C\left(s_{i h}, a_{1 h}, a_{2 h}, m_{h}\right)}{\partial s_{i h}}
$$

determines the optimal schooling investment level $s_{i h}^{*}\left(a_{1 h}, a_{2 h}, m_{h}\right)$ of child $i$. The two schooling decisions will determine optimal family wealth $w_{h}^{*}\left(s_{1 h}, s_{2 h}, a_{1 h}, a_{2 h}, m_{h}\right)$.

We now solve for the optimal consumption allocations. Following Becker, we employ a homothetic utility function $u(\cdot)$. A convenient property of homotheticity is that the expenditure on each consumption good will be a fixed proportion of total wealth. In our context, the utility maximization level of consumption will be

$$
\begin{aligned}
c_{1 h}^{*} & =k_{1 h} w_{h}^{*} \\
c_{2 h}^{*} & =k_{2 h} w_{h}^{*} \\
c_{h}^{*} & =\left(1-k_{1 h}-k_{2 h}\right) w_{h}^{*}
\end{aligned}
$$

where $k_{i h}$ denotes the proportion of total family wealth allocated to child $i .^{6}$ We do not interpret $k_{i h}$ as parental preference parameters. Different values

\footnotetext{
${ }^{6} k_{i h}$ represents the weight parents put on child $i$ 's consumption level in their utility function. To illustrate this point, consider two examples of the parental utility func-
} 
of $k_{i h} \mathrm{~s}$ serve as a convenient form to capture alternative concerns as to why different children may have different levels of consumption. Parents may give more consumption to their older sons not because they "like" them more than the other sons, but because the older sons are more likely to live with them after marriage and provide them elder support. Such dynamic concerns from the parents is embedded in our model through $k_{i h}$. Becker refers to the case where $k_{1 h}=k_{2 h}$ as equal concerns. In our context, equal concerns has no normative implication.

The parents can affect child $i$ 's consumption through two channels: revenue from schooling investment, $R_{i h}^{*}$, and parental transfers, $t_{i h}$. The total consumption of child $i$ is

$$
c_{i h}^{*}=k_{i h} w_{i h}^{*}=t_{i h}^{*}+f_{i h} R_{i h}^{*}
$$

In rural households, $R\left(s_{i h}^{*}, a_{i h}\right)$ may be part of the family agricultural income. Thus not all of it may be appropriated by the child. $f_{i h} \in[0,1]$ is proportion of $R\left(s_{i h}^{*}, a_{i h}\right)$ kept by the child for his own consumption. Substituting in the optimal consumption and schooling investment levels, optimal inter-vivos transfers to child $i$ is therefore

$$
t_{i h}^{*}=k_{i h} w_{h}^{*}-f_{i h} R_{i h}^{*}
$$

So far, we have characterized the parental investment behavior under a framework that allows heterogeneity in both parents and children's attributes, and unequal parental valuations of their investments across children. In the following section, we discuss estimating (6).

\subsection{Empirical specification}

To turn (6) into a regression equation of transfers on schooling expenditure, consider a constant-marginal-return form of revenue $R($.$) on s_{i h}^{*}$ :

$$
R\left(s_{i h}^{*}, a_{i h}\right)=r_{i h} s_{i h}^{*}+e_{i h}
$$

where $e_{i h}$ is a i.i.d random shock with $\operatorname{cov}\left(s_{i h}^{*}, e_{i h}^{*}\right)=0$ and $r_{i h}$ is the marginal rate of return to schooling expenditure.

Substituting the above into (6) to get:

$$
t_{i h}^{*}=k_{i h} w_{h}^{*}-f_{i h} r_{i h} s_{i h}^{*}-f_{i h} e_{i h}
$$

Given a random sample of households $h=1, . ., H$, consider the regression

$$
t_{i h}=\kappa_{i h} F_{h}+\beta_{i h} s_{i h}+\varepsilon_{i h}
$$

$$
\begin{aligned}
& \text { tions. If }(1) U_{h}=c_{h}^{1-\alpha_{1 h}-\alpha_{2 h}} c_{1 h}^{\alpha_{1 h}} c_{2 h}^{\alpha_{2 h}} \text {, then } k_{1 h}=\alpha_{1 h}, k_{2 h}=\alpha_{2 h} \text {; if }(2) U_{h}= \\
& {\left[\left(1-\alpha_{1 h}-\alpha_{2 h}\right) c_{h}^{\rho}+\alpha_{1 h} c_{1 h}^{\rho}+\alpha_{2 h} c_{2 h}^{\rho}\right]^{\frac{1}{\rho}} \text {, then } k_{1 h}=\frac{\frac{1}{1-\rho}}{\alpha_{1 h}^{1-\rho}+\alpha_{2 h}^{1-\rho}+\left(1-\alpha_{1 h}-\alpha_{2 h}\right)^{\frac{1}{1-\rho}}}, k_{2 h}=} \\
& \frac{\alpha_{2 h}^{\frac{1}{1-\rho}}}{\alpha_{1 h}^{\frac{1}{1-\rho}}+\alpha_{2 h}^{\frac{1}{1-\rho}}+\left(1-\alpha_{1 h}-\alpha_{2 h}\right)^{\frac{1}{1-\rho}}} .
\end{aligned}
$$


where $\left\{F_{h}\right\}_{h=1}^{H}$ are household fixed effects, $\kappa_{i h}$ are sibling fixed effects, and $\beta_{i h}$ are the child specific coefficients on schooling expenditure. The estimation and interpretation of $\kappa_{i h}$ and $\beta_{i h}$ warrants detailed discussions.

\subsubsection{Sibling fixed effect $\kappa_{i h}$}

First, unlike the usual specification in the literature, in equation (8), inter-vivos transfers are linear in schooling expenditure but multiplicative in household and sibling fixed effects.

Second, $\kappa_{i h}$ is child dependent. Empirically, we allow $\kappa_{i h}$ to depend a set of binary indicators: whether (1) the son is taller than his sibling, (2) has more agricultural experience at the time of his marriage, (3) has more non-agricultural experience, (4) lived outside the home before marriage, (5) live with the parents after marriage, and (6) he is the first son.

We now discuss the normalization of $\kappa_{i h}$. To ease exposition, let son $i$ in household $h$ be characterized by two indicator variables $D_{i h}=\left(D_{i h}^{a}, D_{i h}^{b}\right) \in$ $\{0,1\} \times\{1,0\}$. Let the sons with $\left(D_{i h}^{a}, D_{i h}^{b}\right)=(0,0)$ be the base group for this group to be $\kappa_{0}$. Not all households have a son where $\kappa_{i h}=\kappa_{0}$. For any type of son $i$,

$$
\kappa_{i h} F_{h}=\left(1+\delta_{a} D_{i h}^{a}+\delta_{b} D_{i h}^{b}\right) \cdot \theta_{h} D_{h}
$$

$\theta_{h}$, estimates $k_{0} w_{h}^{*}$, which is the consumption level enjoyed by a child with hypothetical characteristics $\kappa_{0}$ in household $h . \delta_{a}$ or $\delta_{b}$ is the increase in $k_{i h}$ due to the presence of characteristic $a$ or $b$ for child $i$ relative to the hypthetical child 0 within household $h$.

\subsubsection{Coefficient on schooling investment $\beta_{i h}$}

$\beta_{i h}$ in equation (8) estimates, within a family, the causal marginal effect of a son's schooling expenditure on his bride price. Behaviorally, it is equal to $f_{i h} r_{i h}$ in equation (7). Because of the multiplicative form between $f_{i h}$ and $r_{i h}$, we cannot tell them apart from each other without imposing further assumptions.

\section{$2.2 f_{i h}=1$}

Consider the benchmark case of $f_{i h}=1$ where the child retains all the revenue from his schooling. Then:

Proposition 1 (Homogenous marginal return and full appropriation) If (1) the marginal return to schooling investments is homogenous across children and families $\left(r_{i h}=r\right)$, and (2) children can fully appropriate their schooling returns $\left(f_{i h}=1\right)$, then $\beta_{i h}=\beta$ in equation (8) identifies the marginal return parameter plim $\widehat{\beta}=-r$.

First, the above proposition is true even if we cannot observe abilities of the children. When the gross return to educational investments is homogenous, 
abilities affect the level of investments only through the marginal cost of schooling. Variations in $s_{i h}$ capture all variations in unobservable $a_{i h}$. Therefore $\operatorname{cov}\left(s_{i h}, \varepsilon_{i h}\right)=0$ holds in equation (8).

Second, the marginal benefit of schooling investments should be equalized with marginal cost at the optimum. The marginal cost of schooling should be larger than one with a positive interest rate and if there are non-pecuniary costs to schooling. Then if we observe positive schooling expenditure, the marginal benefit $(r)$ must be greater or equal to one as well. For this reason, proposition 1 imposes two restrictions on the coefficient of schooling investments $\beta$. Not only should it be negative, its absolute value should also be greater or equal to one. This implication is the strong income transfer difference test in our model.

When the two assumptions in proposition 1 are relaxed, the interpretation of $\beta$ will be different.

Proposition 2 (Heterogenous marginal return) If $f_{\text {ih }}=1$ but $r_{i h}=\bar{r}+$ $\psi^{a} \varepsilon_{i h}^{a}$, where $\varepsilon_{i h}^{a}=a_{i h}-E\left(a_{i h}\right)$ and $\psi^{a}>0$, then plim $|\widehat{\beta}|>\bar{r}$.

When the return to schooling is positively correlated with children's unobservable abilities, we are estimating the equation

$$
\begin{aligned}
t_{i h} & =k_{i h} w_{h}-\bar{r} s_{i h}+\eta_{i h} \\
& =k_{i h} w_{h}-\bar{r} s_{i h}-\psi^{a} \varepsilon_{i h}^{a} s_{i h}-e_{i h}
\end{aligned}
$$

If $\operatorname{Cov}\left(s_{i h}, \psi^{a} \varepsilon_{i h}^{a} s_{i h}\right)>0, \beta$ in equation (8) will be biased downwards. In other words, the average marginal return in schooling, $\bar{r}$, will be over estimated.

The next two concerns biases introduced by measurement problems.

Proposition 3 (Unobservable preference bias controls) Suppose that $r_{i h}=$ $r, f_{i h}=1$, and $\operatorname{cov}\left(k_{i h}, s_{i h}\right) \neq 0$. If we cannot perfectly control for $k_{i h}$, then $\operatorname{plim}|\widehat{\beta}| \neq r$.

When $k_{i h}$ is not observed at all, the transfers equation becomes

$$
t_{i h}=\bar{k} w_{h}-r s_{i h}+\left(k_{i h}-\bar{k}\right) w_{h}
$$

Even though $\bar{k} w_{h}$ is picked up with the household fixed effect, $\left(k_{i h}-\bar{k}\right) w_{h}$ will be treated as part of the error terms. It is easy to show that plim $|\widehat{\beta}|=$ $r-\frac{\operatorname{Cov}\left(s_{i h},\left(k_{i h}-\bar{k}\right) w_{h}\right)}{\operatorname{Var}\left(s_{i h}\right)} \neq r$, since $\operatorname{cov}\left(s_{i h}, w_{h}\right)>0$ and $\operatorname{cov}\left(k_{i h}, s_{i h}\right) \neq 0$. This is similar to the standard left out variables problem. A special case is when $k_{i h}$ and $s_{i h}$ are positively correlated through unobservable $a_{i h}$, i.e., parents want to provide more consumption to the smarter children. In this case, plim $|\widehat{\beta}|<r$.

Proposition 4 (Partially observable inter-vivos transfer) Suppose we only observe $t_{i h}^{\prime}=\alpha t_{i h}+\mu_{i h}$, with $0<\alpha<1, \mu_{i h} \sim N\left(0, \sigma_{\mu}^{2}\right)$ and $\operatorname{cov}\left(t_{i h}, \mu_{i h}\right)=0$, then $\operatorname{plim}|\widehat{\beta}|=\alpha r<r$. 
The researcher cannot keep tract of all inter-vivos transfers that are made by parents over their children's lifetime. This proposition indicates a simple case: If the observed transfers are proportional to the real total value, then the coefficient on schooling will be proportional to the gross return in schooling as well.

We use the above proposition to derive a sequential income transfer derivative test. Let the researcher observe two transfers. We can sum these two transfers to get a more complete measure of lifetime parental transfer. Since $\operatorname{plim}|\widehat{\beta}|$ is increasing in $\alpha$, the estimate of $|\beta|$ should be larger for two transfers aggregated compared to the estimate with one transfer measure.

\section{$2.3 \quad f_{i h} \neq 1$}

This subsection discusses the case where children cannot fully appropriate their schooling returns. To simplify the analysis, we maintain the homogeneous schooling returns $\left(r_{i h}=r\right)$. As $f_{i h} \neq 1$, we cannot interpret $\beta_{i h}$ as the marginal return to schooling investments. Even though the model still predicts that $\beta_{i h}=-f_{i h} \cdot r<0,\left|\beta_{i h}\right|>1$ may not hold. Thus the strong income transfer difference test is not valid. The sequential income transfer difference test remains valid.

The fraction of the schooling returns that children can retain for themselves may depend on the children's attributes. For example, consider two sons both working as farmers after the marriage. One lives with his parents while the other does not. $f_{i h}$ should be lower for the former because when he acquires more education, the parents' farm output will gain from better decisions made by a better educated son. Yet this son may be unable to appropriate the extra return relative to his brother who moved away. To test this, we assume that

$$
f_{i h}=\left(1+\rho_{a} D_{i h}^{a}+\rho_{b} D_{i h}^{b}\right) f_{0}
$$

We take sons with $\left(D_{i h}^{a}, D_{i h}^{b}\right)=(0,0)$ as the base group and denote the fraction of schooling returns they can keep for themselves as $f_{0}$. To identify the parameters, consider a regression

$$
t_{i h}=k_{i h} w_{h}+\beta s_{i h}+\gamma_{1} D_{i h}^{a} s_{i h}+\gamma_{2} D_{i h}^{b} s_{i h}+\varepsilon_{i h}
$$

with both schooling expenditure and and its interactions with children's attributes. Relationships between the coefficients in (12) and the parameters in (11) are

$$
\begin{aligned}
\beta & =-f_{0} r<0 \\
\gamma_{1} / \beta & =\rho_{a} \\
\gamma_{2} / \beta & =\rho_{b}
\end{aligned}
$$

The sign of $\rho_{a}$ tells us which sons can appropriate a higher proportion of their schooling returns. In table A4, we show the signs of $\rho$ we expect for different 
children's attributes. The main occupation of the parents in our sample is farming. Parents will benefit more from their sons' education when their sons participate in agricultural activities or live with them after marriage. If $D_{j h}^{a}$ is a indicator of "living with the parents after marriage", then we shall expect $\rho_{a}<0$. Traditionally, the first son usually takes more responsibility to take care of his parents and siblings. This is why we expect they will get relative less of their human capital returns. By contrast, sons with more non-agricultural experience or live independently tend to have less contact with their parents. The proportion of education returns that these sons can keep will be higher.

To sum up, the full specification we want to estimate, without restricting $f_{i h}=1$, is

$$
t_{i h}=\left(1+\delta_{a} D_{i h}^{a}+\delta_{b} D_{i h}^{b}\right) \cdot \theta_{h} D_{h}+\beta s_{i h}+\gamma_{1} D_{i h}^{a} s_{i h}+\gamma_{2} D_{i h}^{b} s_{i h}+\varepsilon_{i h}
$$

The identified parameters are $(\delta, \theta, \beta, \gamma)$. They will be estimated through nonlinear least squares. Refer to the appendix for the detailed estimation algorithm and econometric issues including the incidental parameters problem.

\section{Data}

The data used in this study come from the "Survey on Family and Marriage Dynamics in Hebei Province", which was carried out in the summer of 2005 by the authors and some Chinese colleagues. Hebei province is a representative of North China culturally, economically, and socially. We focus on its rural villages. (Refer to figure 1 for a map and detailed sampling strategy.)

In rural Hebei, most children go to work after they finish school. Their parents shoulder almost all of their educational expenditure. Self-financing is negligible. Figure 2 illustrates the dynamics of educational expenditure changes in our sample. Total educational expenditure on sons in 1980 yuan increased significantly along with household annual income since the economic reform. After the late 1980s, the speed of increase slowed down. The total expenditure that a household spent on sons' education amounts to about four fifths as much as of annual household income. Increases in education expenditure were mainly due to the increase in years of schooling, rather than increases in tuition fee (Refer to figure A2). ${ }^{7}$

As for parental transfers, we consider a significant inter-vivos transfer in rural Hebei: marital transfers. Currently, a large part of the marital transfers in rural Hebei is given by parents to their marrying children, not their in-laws. It is an inter-generational transfer rather than an inter-familial transfer. At the time of the marriage, both the groom's and the bride's families provide furniture, major home appliances, agricultural equipment, and sometimes cash

\footnotetext{
${ }^{7}$ We also examine daughters' educational expenditure over the same period. From the beginning of the economic reform till mid 1990s, total investments in boys' education is way more than those in girls' education. Since 1990, girl's education expenditure has been catching up very quickly. After mid 1990s, investments in children's human capital are about the same between genders.
} 
payments to the newly-wed couple. ${ }^{8}$ The groom's family usually spend more because traditionally the groom is responsible for building a new house for the newly weds. Parents have to save for years in order to finance such expenditure. Escalating marital expenses in Chinese villages during the past two decades have been well documented in the literature (e.g. Siu, 1993; Min and Eades, 1995; Zhang, 2000).

Our dataset confirms a high and rising bride-price since the economic reform. Refer to figure 2. Despite some fluctuations in early 1990s and 2000s, the brideprice is usually two and a half times as much as annual household income. Household saving rate in rural China is about 0.3 . (*** Reference ${ }^{* * *}$ ) In this sense, it will take parents about 7 to 8 years to accumulate the bride-price. ${ }^{9}$

The survey was designed to address some of the issues discussed in the previous section. Each household had to have at least one married child in order to be included in the sample. Respondents in our survey are parents in the household with age from 50 to 69 . We do not visit parents older than 70 because the recall error will be a serious issue. Parents were interviewed for information on their children, which provided us with an unique opportunity to explore withinhousehold variation. To alleviate the burden of the interview, for households with more than three married children, three of them were selected. ${ }^{10}$ For each child, significant events over his/her life time were recorded, including (1) education, (2) premarital work experience, (3) marriage process and information on in-laws, (4) fertility and post-marriage intra-family arrangements and (5) pre-mortem household division if applicable. Altogether, the dataset contains 600 households with 1688 children (853 sons and 830 daughters), among which 1276 (628 Sons and 648 daughters) have been married.

In this paper, we focus on parental transfers toward sons. The main reason of this sample restriction is that nearly all sons receive strictly positive marital transfers. When both sons receive positive transfer, these transfers decisions come from interior solutions to the parents optimization problem. Therefore the two-step maximization is valid and all implications of our model should apply. The same argument does not hold for daughters, where about 20 percent of the sampled daughters does not receive any dowry. In these cases, implications of the model's corner solution have to be derived, which is beyond the scope of this paper.

\footnotetext{
${ }^{8}$ Actually, the cash transfer paid by the groom's family, which accounts for about 20 percent of the bride price, is usually given directly to the bride's family. However, once the bride's parents receive this cash payment, they can either keep it or use it to purchase items for the dowry. Such dowry financed by cash components from the bride-price is often referred to as "indirect dowry" in the sociology literature (see Goody (1978)). According to our dataset, on average, nearly all of the cash in bride-price become indirect dowry. This suggests that cash parts in bride price should be taken counted as the marital transfers enjoyed by the grooms, even though they are initially given to the bride's parents as inter-familial transfers.

${ }^{9} \mathrm{By}$ contrast, dowry is normally half of the annual household income.

${ }^{10}$ The selection criteria were: (1) Choose the children who married first and last; (2) If the two selected children are of the same sex, choose a third of the opposite sex; (3) If the two selected children are of different sex, choose a third one about whom the parents were most worried when s/he was 15; (4) If none of these criterion are applicable, daughters are preferred.
} 
There are 178 households with more than 1 married son in our dataset. Further restrictions have to be imposed for purpose of our analysis. First of all, children with missing values for education expenditure or marital transfers were dropped. There were 16 households, less than 10 percent, when the groom's family did not pay any bride-price. We exclude them in our analysis, as they did not represent the marriage arrangement we usually observe. We also exclude 18 matrilocal marriages,${ }^{11}$ since this marriage pattern deviated from the mainstream patrilocal custom in the region. We keep all households with more than 1 married son surviving the above criteria. In the end, 127 households with 264 sons/grooms are used in the analysis of this paper.

Table 1 presents descriptive information on the characteristics of these households and their children. To show the relative importance of the between-sibling variations in our dataset, we calculate for variables at the individual level the within-household standard deviations in column 4 . The results are generally half of the overall standard deviations (column 3 of Table 1). Column 5 reports the number of households with within-household variations in children's characteristics.

For each child in our dataset, education expenditure was reported since middle school (grade 7). It included tuition fees, boarding expenses and other living expenses, deflated to 1980 price levels. We do not record expenditure in elementary schools, because measurement error could be a significant problem as most parents could not accurately recall such information. Instead, we impute the spending on elementary school for each child. A recent study by Liu et al. (2006) shows that the total cost of elementary education is about half the cost of middle school education in rural China. In light of this, we regress observed middle school expenses on gender, cohort and village dummies, and halve the predicted value before using it as imputed elementary schooling expenditure. ${ }^{12}$

Marital transfers in rural Hebei usually include cash and items, such as furniture, home appliances and agricultural equipment, etc. Some groom's family build a new house for the couple. In our dataset, for each marriage, we have a complete inventory of marital transfers along with their monetary value. The dependent variable in our regressions is defined by the total real value of the bride-price. On average, marital transfers received by sons are three times larger than their educational investments.

Sons examined in this paper were born between the 1950s and the 1990s, and most marriages took place between 1980 and 2000. Mean age at marriage was 23 . Before marriage, sons tend to participate in more agricultural activities than non-agricultural activities.

Compared with their children, parents have many fewer years of schooling. The difference in education between gender is larger for parents. The illiteracy rate is $35 \%$ for fathers and $67 \%$ for mothers.

Some family wealth indicators are constructed. For the interviewed parents, we have a complete list of the houses built by parents since they married. Fur-

\footnotetext{
${ }^{11}$ Matrilocal marriages are marriages where newlywed couples live in or near the household of the bride's natal family.

${ }^{12}$ The mean of this imputed variable is around 300 yuan.
} 
thermore, we know all agricultural investments in livestock and equipment made by the household. We use the average real value of housing and total value of agricultural investments as proxies for family wealth.

\section{Empirical Results}

\subsection{Estimation and interpretation under the assumption $f_{i h}=1$}

Columns (1) to (8) in Table 2 report the estimation results for equation (8) with various children's attributes as controls for $k_{i h}$. These attributes include: the indicator of being the taller son in the household, indicators of having more agricultural or non-agricultural experience in the household, the indicator of living with parents before or after marriage, and the indicator of being the first son. ${ }^{13}$ The "hypothetic" son for comparison in each household will have zero values in all of these dummies. In column (8), we only select the significant factors in the full specification in order to focus our discussions.

The point estimate of $\beta$ using OLS without any other covariate in column O1 is -0.23 with a standard error of 0.06 . Since marital transfer and schooling expenditure is positively related to household income, the estimate of $\beta$ is biased upward without controlling for household income. Column O2 adds household fixed effects to the regression and the estimate of $\beta$ is -0.39 with a standard error of 0.15 . Controlling for household fixed effects decreases our estimate of $\beta$ in the direction predicted by the theory.

As we add different household and sibling interaction effects individually, the point estimates for $\beta$ generally stay around -0.35 . Our preferred specification is in column (8). Here, compared with the "hypothetical son" in the household, taller sons enjoy 22 percentage more in total consumption. Sons who live with their parents after marriage obtain nearly 40 percent more consumption than those do not. Lastly, older sons tend to get one fifth less than their younger siblings, which at first sight is inconsistent with popular wisdom about first son bias in rural China. Below, we will show that this inconsistency is resolved with appropriate discounting.

The results also suggest that parents tend to provide more consumption to children with more premarital agricultural or non-agricultural experience, and to children who do not live outside the home before marriage (column (7)). Even though these coefficients are imprecisely estimated, their magnitude suggests

\footnotetext{
${ }^{13}$ In an unreported specification, we try to control for years effects using sons' (1) age at marriage and (2) age at the time of the survey. The former's coefficient is -0.02 and statistically insignificant. The latter carries a significant coefficient of -0.05 , suggesting that one will receive 5 percent less in consumption if he is 1 year older than his brother. As we shall see later, this result is consistent with what we obtain from the first son dummy. However, it is not wise to put the "first son indicator" and "age" in the same regression since they are highly correlated. Given that our main conclusions are not affected in either way, we decide not to put these time controls in our final regressions.
} 
that they are not economically insignificant. ${ }^{14}$

Estimates of $k_{0} w_{h}$ are summarized in Table A2. Panel A and B show the summary statistics and distribution of $k_{0} w_{h}$ estimated under different specifications in Table 2. Both the graph and the Kolmogorov-Smirnov statistics show that the distributions of $k_{0} w_{h}$ are not significantly different from log-normal. In panel $\mathrm{C}$, we examine the determination of $k_{0} w_{h}$, by regressing it against household level characteristics. The estimates are consistent across columns. Coefficients on number of sons and daughters in the household are negative, suggesting that the hypothetic son enjoys less consumption if there are more sons or more girls in the family. The consumption level is also higher in families that are richer, or with better educated household head, or located in richer counties.

According to proposition 1, with $r_{i h}=r$ and $f_{i h}=1$, the coefficient on schooling expenditure should be interpreted as the marginal return to educational investments. It should not only be negative, but also have a magnitude greater than 1 .

The coefficients on schooling investments are significantly negative in table 2, providing evidence for intra-household compensatory behavior. The magnitude varies from 0.2 to 0.4 which does not support the unitary model under the strong income transfer difference test.

What may cause the under estimation in $r$ ? First, we can rule out the case of heterogeneity in marginal schooling returns, since the bias in that case go to the opposite direction (see proposition 2). Second, according to proposition 3 , if parents are biased toward children with unobservable endowments, our estmates of $r$ may be biased downwards. But this conjecture cannot be verified since we do not have proper instruments for abilities. In the following sections, we will focus on several testable alternatives that may close the gap between our estimates of $r$ with its predicted value.

\subsubsection{Sensitivity to discount rates}

The framework discussed in the section 2 is a static model while actual intrahousehold transfers are made over time and in different periods for different children. To make these transfers comparable in present value, all transfers made in each household are discounted at rate $d$ to the year in which the first son got married. Refer to column (1)-(6) of Table 4, where we compare different specifications (the basic ones assuming "equal concerns" and the parsimonious ones with only the significant controls) under different discount rates in order to test the sensitivity of our results.

There are several patterns in Table 4. First, coefficients on schooling investments become smaller in magnitude as the discount rate increases. Therefore, taking the discount rate into account does not solve our problem of underestimating $r$. Second, estimates of $\delta$ do not vary across different discount rates either in terms of their magnitudes or standard errors, except for a time related

\footnotetext{
${ }^{14}$ If we plot the confidence intervals of these estimates, most of the intervals will fall into a range far from zero.
} 
factor: the first son indicator. Coefficients on the first son dummy consistently increase with discount rates, and become positive eventually.

These trends are due to the nature of discounting. Educational expenditures occurred before marital transfers. If we discount everything to the time when the first son got married, ${ }^{15}$ the difference in education expenditure across siblings by age will be enlarged. Meanwhile, the difference in marital transfer by age will be compressed. So discounting increases the value of schooling expenditure of the first son and reduces the value of marital transfers to the second son. This logic explains why the estimates of the first son effect increases with the discount rate.

\subsubsection{Measurement error in schooling investments}

The low value of the coefficients on education expenditure may be due to the attenuation bias. Given that our education expenditure variable mainly comes from recall data, measurement error might exist, which could bias OLS estimates towards zero. One way to correct for this bias is to adopt an instrumental variable approach. "Years of schooling" is an ideal candidate to serve as an instrument for education expenditure: (1) it is positively correlated with education expenditure and (2) its measurement error, if there is any, is not likely to be correlated with that of the education expenditure.

In Panel A of Table 5, we replicate all specifications in table 4 with 2SLS estimation. The first stage regressions and reduced form regressions are presented in Panel B and Panel C, respectively.

As expected, "years of schooling" is a good predictor of education expenditure in the first stage. (One year of schooling costs about 800 yuan on average.) However, the second stage increases the standard errors and leads to a loss of precision in the estimates of all the coefficients. Compared with the OLS results, the magnitude of the IV estimates are slightly smaller, but the Hausman tests cannot reject that their difference is statistically insignificant. We conclude that the underestimation of $r$ is not likely due to the attenuation bias.

The reduced form results suggest that one year extra year of schooling only contributes about 120 yuan increase in life-time consumption (see preferred specification with discounting rate 0.05), which is much lower than the monetary cost suggested by the first stage results. It is not surprising that such a low estimate in marginal return to schooling is consistent with our low point estimates in marginal return to schooling expenditure.

\subsubsection{A sequential income transfer difference test}

Parents may use other forms of transfers than marital transfers to make up the difference in human capital investments among their children. Proposition 4 says that when we use a part of the life-time transfers to estimate equation (12), $r$ will be biased downwards. To address this issue, we consider another significant parental transfers captured in our survey: the pre-mortem bequest.

\footnotetext{
${ }^{15}$ Choosing a different timing as baseline for discounting will generate the same trend.
} 
Some families in our sample have made household property divisions before the parents pass away. ${ }^{16}$ These pre-mortem bequest include housing, land, and other items such as agricultural equipment. 75 percent of our households have divided the house, 65 percent of the households have divided the land, and a few households (about 10 percent) have also divided other items. Value of housing and items are reported. For land divisions, we know the sizes of the land and the time of inheritance. Value of the land is calculated as the total real return from cultivation over the first 10 years after the land is given to the son. Panel A of Table 6 reports the summary statistics for each part of pre-mortem bequest. Notice that value of the housing given at the time of the marriage represents a large share of the total value of the bequest, but those have been counted as part of the bride-price. Therefore, the land property is the only important transfer besides the marital transfers captured by our data. ${ }^{17}$

By adding up these two transfers, we can construct a more complete measure of life-time parental transfers and investigate its impact on our estimates of $r$. We re-estimate equation while adding the value of land into the dependent variable $\left(t_{i h}\right)$. The regressions are estimated using the subsample of households that have made land divisions. The results are reported in the panel B of Table 6 . Consistently with the proposition 4 , for the same specification and discount rate, taking into account the value of inherited land substantially increases the absolute value of the coefficients on schooling expenditures. ${ }^{18}$ This result is robust across all discount factors. For example, with a ten percent discount rate, our preferred specification in column 6 now suggests $r=0.37$ rather than 0.16 . That is, the estimated compensatory coefficient has more than double when we are able to capture more of lifetime parental transfers.

Moreover, magnitudes of the parental bias parameters becomes smaller but with similar standard errors as before. Overall, they become statistically insignificant. However, their signs are the same and the patterns under different discount rate remain as in Table $4 .^{19}$

Our theoretical model predicts that estimating equation (8) using a partial measure of parental transfer will underestimate $r$. Our empirical results in

\footnotetext{
${ }^{16}$ It should be noticed that only 20 percent of these divisions rely on formal written contract. Most of them are based on consensus within the household. In addition, daughters in rural China are not entitled to any forms of bequests. Only sons are potential recipients.

${ }^{17}$ In fact, other than marital transfers and household divisions, we ask in our questionnaire about the information on every transfer larger than 100 yuan that parents give to the children after their marriages. It turns out that only 43 sons (16 percent of total sample of sons) receive post-marital transfers, with an average of 1700 yuan. This value is only about one third of the mean bride-price these sons received. The evidence suggests that offering a large amount of post marital transfers is not a common practice in rural Chinese villages.

${ }^{18}$ Even though the difference is not statistically significant at times due to the larger standard errors.

${ }^{19}$ The difference we observe may due to the fact that we are using a more restricted sample. To address this concern, we replicate marital transfer regressions in table 3 using the same subsample as table 6 . The results are shown in table A3. The coefficients on schooling expenditures and parental bias factors in this table are very similar with those in table 3 , suggesting that the increase in estimates of $\mathrm{r}$ in table 6 cannot be attributed to the sample selection.
} 
Table 4 and 6 shows that this concern is empirically significant. Even under the assumptions $f_{i h}=1$ and $r_{i h}=r$, this finding suggests that using partial measures of lifetime transfers and lifetime incomes to equate the strong income transfers difference tests as a test of the unitary model is likely to be misleading. The sequential income transfer difference test is informative about the unitary model when one has multiple measures of parental transfers as we do here. Our empirical evidence using this alternative test provides support for the unitary model.

\subsection{Estimation and interpretation under the assumption} $f_{\text {ih }} \neq 1$

In traditional agriculral societies, families farm together. So a child may not fully appropriate the economic return to his or her education. Based on our model, when children cannot fully appropriate their schooling returns, the coefficient on schooling expenditure cannot be interpreted as only the marginal return, but rather as the marginal consumption directly captured by the child (see equation (7)). Unfortunately, because of the multiplicative form between $f_{i h}$ and $r$, it is not possible to identify them separately. As discussed in the model section, we expect the proportion of returns that children can keep for themselves to depend on their activities and living arrangements with the parents (see Table A1). These patterns can be tested by examining the interaction terms between schooling expenditure and children's attributes in equation (16).

Table 3 reports the results. In each specification from column (1) to (8), we interact the same attributes with schooling investments as what we control for the parental bias. ${ }^{20}$

The first thing to notice is that our estimates $\gamma_{\mathrm{S}}$ in equation (16) are very imprecise. The large standard errors are mainly due to our relative small sample size. Secondly, because of the weak explanation power of the interaction terms, ${ }^{21}$ adding them into the regressions do not significantly alter our estimates of $\beta$ and $\delta$ s (comparing Table 3 with Table 2 ). But we should keep in mind that the interpretation of $\beta$ is different under the assumption of $f_{i h} \neq 1$ : it identifies the consumption of the "base group" son from each yuan spent in schooling (see equation (13)).

While imprecisely estimated, most estimated interaction terms in Table 3 have the predicted signs (as Table A1). When sons engage in agricultural activities or are co-resident with their parents, their parents will benefit more from their schooling and they tend to retain less of their schooling returns. In Table 3 column 7 , sons living with parents before marriage or after marriage retain less income from schooling investments. ${ }^{22}$ The first sons are also found to directly

\footnotetext{
${ }^{20}$ We also try specifications where all of the attributes are interacted with the schooling investments regardless the way we control for $k_{i h}$. The conclusions are essentially the same.

${ }^{21}$ Notice that Table 2 and 3 have the same $R^{2}$ for all specifications.

${ }^{22}$ However, this coefficient switches sign once other interaction terms are controlled simultaneously (compare column 2 and 7 ). This may be due to the collinearity between the agriculture and non-agriculture experience indicators.
} 
benefit less from schooling than their siblings. By contrast, sons with more non-agriculture experience tend to get 0.17 yuan more from each yuan spent on schooling, consistent with the view that their parents as farmers are less likely to benefit directly from them. On the other hand, sons with more agricultural experience retain more of their schooling returns which is anamolous.

The last three columns in Table 4 show that our main conclusions are robust to different discounting rates. Instrumenting schooling expenditure by years of schooling does improve the precision of the estimates of $\delta^{\prime}$ (column 7-9 of table 5). Columns 7-9 in Table 6 show that aking the value of land division as parts of the parental transfers do not change the point estimates of $\delta^{\prime} s$ substantially from that in Table 4.

As a conclusion of this section, we find evidence suggesting that sons in our sample may not fully appropriate the total returns to their schooling. However the large standard errors preclude us from being able to make precise quantitative statements on the degree of appropriation based on the sons' attributes.

\section{Other Issues}

\subsection{Public goods in returns to schooling}

Consumption of the schooling returns can be non-exclusive as well. If the son uses his income to refurnish the house with better furniture and home appliance, parents living with him benefit too. In this case, sons obtain the full returns to schooling, but a proportion $\left(f_{i h}\right)$ of the returns is public goods. ${ }^{23}$ It turns out that we can interpret the coefficient on schooling expenditure as the marginal return parameter regardless the value of $f_{i h}$. Therefore, our low point estimate in $r$ cannot be explained by the public goods story.

Proposition 5 (Public Goods Component in Returns to Schooling) If in the total returns to schooling investments $r$ s, a fraction of $f_{\text {ih }} \in(0,1)$ is public goods that can be consumed by both the son and parents, then plim $|\widehat{\beta}|=r$.

The proofs are included in the appendix. Notice that now the schooling investments generate extra benefit to the parents $\left(f_{i h} r s_{i h}\right)$. The optimal schooling investments will be higher compared to our baseline model.

\subsection{Regressions where sibling effects and household fixed effects enter linearly}

In this section we present the results of commonly-used regression where both household fixed effects and sibling fixed effects enter linearly. Refer to Table

\footnotetext{
${ }^{23}$ It should be noticed that, other than the returns to schooling, marital transfers can be public goods as well. If parents live with their son post marriage, their living condition will be improved by the house and appliances built and purchased for the couple. The result is very similar with the public goods in schooling returns case. Therefore we do not state it as a separate proposition.
} 
A5. We run the regressions using both level-on-level form (Table A5.1) and logon-log form (Table A5.2), with (panel As) and without household fixed effects (panel Bs) ${ }^{24}$ Across columns, we put in different indicators to capture "unequal concerns" across siblings.

Controlling for household level heterogeneities is crucial to obtain consistent estimates. Without household fixed effects, the coefficients on schooling investments are significantly negative in level regressions and insignificant (sometimes even positive) in log form regressions. After adding in household dummies, the coefficients are substantially smaller (more negative) and significant throughout all specifications. Richer families tend to invest more in both education and inter-vivos transfers to their children, therefore simple OLS regression will bias the coefficients on schooling investments upwards if we cannot perfectly control for family wealth. From now on, we will focus our attentions on household fixed effect regressions.

The level regressions suggest that when one son receives 1 yuan less in his schooling investments than his brothers, he will be compensated by about 0.28 to 0.38 yuan in his marital transfers. The log form regressions support similar compensation story.

As to the parental bias indicators, level and log regressions occasionally produce different sign, but they are generally not significantly different from zero. Notice that some of the indicators do have significant economic effect. For example, sons living with their parents after marriage receive more than 1000 yuan than their brothers in marital transfers. However, the larger standard error of this estimates prevent us from drawing any inference at conventional confidence level.

In the literature, researchers use these level and log regressions while maintaining the "equal concern" assumptions. However, once we relax this assumption and add in indicators to control for the parental bias, these specifications are problematic. For example, if parents love their first son 10 percent more than the others, they will give him 10 percent, rather than 0.1 yuan, more in marital transfers. Hence it is not sensible to put sibling indicators linearly in level-on-level regressions. The log-on-log specification has its own problem too. It does not allow marital transfers to be zero. When marital transfers take values close to zero, it requires schooling expenditure close to infinity. In a word, both of these two specifications lack micro foundations. It is unclear what kind of household decision model will generate specifications like level-onlevel or log-on-log. And it is unclear how we should interpret and evaluate the magnitude of our coefficients. In this sense, our multiplicative specification has its advantages. Empirically, using our specification, we manage to obtain more significant evidence in parental biases in intergenerational transfers which is not so obvious in linear regressions.

\footnotetext{
${ }^{24}$ Family level attributes, such as father's years of schooling, total number of sons and daughters, and wealth indicators are also added in regression without household fixed effects. To save spaces, these coefficients are not reported.
} 


\subsection{Strategic behavior of the children}

So far, our framework assumes children are passive and only parents make decisions in the family. This assumption can be relaxed without changing the model's implications as long as Becker's "Rotten Kid Theorem" applies. Becker (1974, 1991) argues that parental transfers force children to consider parents' interests. Active, selfish children will choose actions that maximize total family wealth, which is the only factor that determines their consumption level under the transfer scheme. In this case, the outcome will be the same as the two-step maximization problem solved by the parents.

There are, however, circumstances when "Rotten Kid Theorem" fails. Bergstrom (1989) argues that the theorem will not hold if utility depend more than transferable commodities. We discuss two examples with this feature. Both examples are Stackelberg games, where parents make their choices first while taking the response of children into account.

First, if children with higher education are more likely to study outside the village (mostly in the cities), they will have higher chance to work in nonagriculture sector and will not return. Taking this into account, parents with preference on co-residence with their children may reduce children's schooling investments just to the level to keep their children staying around. In this case, schooling investments may not be efficient.

Second, full compensation in transfers amounts to a full insurance provided to the children. If the return to education depends on the efforts that children spend on their study, two problems would come into presence: free riding (among siblings) and moral hazard. Both of them would cause the children to exert less effort than the optimal levels. To avoid these problems, parents would break the linkage between education achievement and inter-vivos transfer and commit an equal amount of transfers to their children. In this case, wealth equalization would be violated, the efficiency, however, could be achieved. Such strategic behaviors tend to drive the coefficient on education investment towards zero in our regression.

\section{Conclusion}

This paper constructs an empirical unitary model of parental investments and allocation of their children's consumption which incorporates unobserved family heterogeneity, unequal parental valuations of their investments across children, and unobserved differences in children's abilities. In addition to a standard income transfer difference test, we also provide a sequential income transfer difference test based on the availability of multiple parental transfer measures. We also argue that the strong income transfer test in our context, a traditional agricultural society, is likely to be invalid.

Empirically, parents transfer more consumption to sons who are better endowed or who live together with them post marriage. Bias towards the first son is sensitive to the discount rate we use when comparing transfers given at 
different point in time.

Controlling for the parental bias, parents compensate for the difference in schooling investments they made in their children. In particular, sons receiving 1 yuan less in schooling will be compensated by getting 0.4 yuan extra in his marital transfers. Our interpretation of this estimate depends crucially on the assumption about the proportion of schooling benefits that sons can retain for themselves $\left(f_{i h}\right)$.

When $f_{i h}=1$, the coefficient on schooling investments identifies the marginal return to schooling investments, and is supposed to take a value greater than or equal to 1 . From our empirical evidence, our low point estimates cannot be explained by (1) measurement errors in schooling expenditure, (2) choice of discount rates, (3) heterogeneous returns to schooling, and (5) public goods components in children's consumption. Instead, we find that adding other parental transfers into the dependent variable can significantly increase magnitude of the coefficient on schooling expenditure to 0.7 , indicating the importance of having a measure close to lifetime transfers when testing this model. The sequential income transfer difference test provides support for the unitary model.

When $f_{i h} \neq 1$, the coefficient on schooling investments identifies the marginal consumption obtained by sons from each yuan spent in their schooling, whose magnitude may not be greater than 1. By examining the interaction terms between children's attributes and schooling expenditure, we find weak evidence suggesting that children's activities and living arrangement with their parents affect the proportion of schooling benefits they can keep for their own consumption. 


\section{References}

[1] Altonji, Joseph G., Hayashi, Fumio and Kotlikoff, Laurence J. (1992). "Is the Extended Family Altruistically Linked? Direct Tests Using Micro Data", The American Economic Review, Vol. 82, No. 5, pp. 1177-1198

[2] Altonji, Joseph G., Hayashi, Fumio and Kotlikoff, Laurence J. (1997). "Parental Altruism and Inter Vivos Transfers: Theory and Evidence", The Journal of Political Economy, Vol. 105, No. 6, pp. 1121-1166.

[3] Becker, G. S. (1991). A Treatise of the Family, enlarged edn, Harvard University Press, Cambridge, Massachusetts.

[4] Becker, G. S. (1974). A theory of Social Interactions. Journal of Political Economy, 82 (6), 1063-1093.

[5] Becker, G. S. and Tomes, N. (1976). "Child Endowments and The Quantity and Quality of Children", The Journal of Political Economy, 84 (4, part2): S143-S162.

[6] Behrman, J.R., R.A. Pollak and P. Taubman (1995), "The wealth model: efficiency in education and equity in the family", in: J.R., Behrman, R.A. Pollak and P. Taubman, eds., From parent to child: intrahousehold allocations and intergenerational relations in the United States, University of Chicago Press, Chicago, IL.

[7] Black, Sandra E, Paul J Devereux, Kjell G Salvanes (2007). "From the Cradle to the Labor Market? The Effect of Birth Weight on Adult Outcomes", Quarterly Journal of Economics, Vol. 122, Issue 1, pp. 409-439.

[8] Cox, R. (1987). "Motives for private income transfers", The Journal of Political Economy, 95 (3): 508-546.

[9] Cox, R. and Rank, M. R. (1992). "Inter-vivos Transfers and Intergenerational Exchange", Review of Economic Studies, 74 (2): 305-314.

[10] Dunn, T. A. and Phillips, J. W. (1997). "The Timing and Division of Parental Transfers to Children", Economics Letters, 54: 135-137.

[11] Goody, Jack, (1973) "Brideprice and Dowry in Africa and Eurasia", in Bridewealth and Dowry, edited by Jack Goody and Stanley J. Tambiah. Cambridge Papers in Social Anthropology, no. 7. Cambridge: Cambridge University Press.

[12] Haider, S. J. and McGarry, K. (2006). "Parental Investments in Education and Later Financial Transfers: A Preliminary Look", Working Paper.

[13] Hochguertel, S. and Ohlsson, H. (2007). "Compensatory Inter Vivos Gifts", Working Paper. 
[14] Kim, H. (2005). "Parental Investment between Children with Different Abilities", Working Paper.

[15] Liu, M., Xu, Z., Tao, R. and Su, X. (2006). "Study on the Dynamics of Famer's Education Fees Burden before and after the Rural Tax Reform", Working Paper.

[16] Menchik, P. (1980). "Primogeniture: equal sharing and the US distibution of wealth", Quarterly Journal of Economics, 95: 299-315.

[17] Menchik, P. (1988). "Unequal estate division: is it altruism, reverse bequests or simply noise?", in: D. Kessler and A. Masson, eds., Modelling the accumulation and distribution of wealth (Oxford University Press, Oxford).

[18] McGarry, K. and Schoeni R. F. (1995). "The Transfer Behavior in the Health and Retirement Study: Measurement and the Redistribution of Resources within the Family". Journal of Human Resources, Vol. 30, No. 0, Special Issue on the Health and Retirement Study: Data Quality and Early Results. (1995), pp. S184-S226.

[19] McGarry, K. (1999). "Inter vivos Transfers and Intended Bequests," Journal of Public Economics, 73 (3): 321-351.

[20] McGarry, K. (2006). "Testing Parental Altruism: Implications of a Dynamic Model", NBER wokring paper (7593).

[21] McGarry, K. and Schoeni, R. F. (1995). "Transfer Behavior in the Health and Retirement Study: Measurement and the Redistribution of Resources within the Family", Journal of Human Resources, 30 (0): S184-S226.

[22] Min, H. and Eades, J. S. (1995). "Brides, Bachelors and Brokers: The Marriage Market in Rural Anhui in an Era of Economic Reform", Modern Asian Studies, 29 (4): 841-869.

[23] Mincer, Jacob (1974), Schooling, experience and earnings, Columbia University Press, New York.

[24] Raut, L. K. and Tran, L. H. (2005). "Parental human capital investment and old-age transfers from children: Is it a loan contract or reciprocity for Indonesian families?", Journal of Development Economics, 77: 389-414.

[25] Siu, H. F. (1993). "Reconstituting Dowry and Brideprice in South China", Chinese Families in the Post-Mao Era, University of California Press, pp. 139-164.

[26] Zhang, W. (2000). "Dynamics of Marriage in Chinese Rural Society in Transition: A Study of a Northern Chinese Village", Population Studies, 54: 57-69. 


\section{Appendix A: Estimation of the Multiplicative Model}

Given a random sample of households $h=1, . ., H$, each with 2 children $i=1,2$, consider the regression

$$
\begin{aligned}
y_{i h} & =K_{i h} \cdot W_{h}+X_{i h} b+\varepsilon_{i h} \\
& =\left(1+D_{i h} \delta\right) \cdot W_{h}+X_{i h} b+\varepsilon_{i h}
\end{aligned}
$$

where $y_{i h}$ is the dependent variable; $D_{i h}$ and $X_{i h}$ are vectors of children's characteristics; $W_{h}$ are the household fixed effect. The parameters to be identified are $\theta=\left(\delta,\left\{W_{h}\right\}_{h=1}^{H}, b\right)$.

In our context, comparing (18) with (16), we can see the following correspondence:

$$
\begin{aligned}
y_{i h} & =t_{i h} \\
D_{i h} & =\left(D_{i h}^{a}, D_{i h}^{b}\right) \\
W_{h} & =k_{0} w_{h} \\
X_{i h} & =\left(s_{i h}, D_{i h}^{a} s_{i h}, D_{i h}^{b} s_{i h}\right) \\
b & =\left(\beta, \gamma_{1}, \gamma_{2}\right)
\end{aligned}
$$

A nonlinear least squares (NLS) estimator of $\theta, \widehat{\theta}$, solves

$$
\min _{\theta} \sum_{h=1}^{H} \sum_{i=1}^{2}\left(y_{i h}-K_{i h} \cdot W_{h}-X_{i h} b\right)^{2}
$$

To release the computational burden of global searching for all parameters $(H+3$ dimensions), we take advantage of the partial linearity in (18): conditional on $K_{i h}$, equation (18) is a linear model and $\left\{W_{h}\right\}_{h=1}^{H}$ and $b$ can be estimated through OLS. Denoting these estimators as $\left\{W_{h}^{\text {ols }}\left(K_{i h}\right)\right\}_{h=1}^{H}$ and $b^{\text {ols }}\left(K_{i h}\right)$, our problem is to find $\widehat{\delta}$ that solves

$$
\min _{\widehat{\delta}} \sum_{h=1}^{H} \sum_{i=1}^{2}\left(y_{i h}-\widehat{K_{i h}} \cdot W_{h}^{\text {ols }}\left(\widehat{K_{i h}}\right)-X_{i h} b^{\text {ols }}\left(\widehat{K_{i h}}\right)\right)^{2}
$$

where $\widehat{K_{i h}}=1+D_{i h} \widehat{\delta}$. Once we obtain $\widehat{\delta}$, the final estimator $\widehat{\theta}$ is

$$
\widehat{\theta}=\left(\widehat{\delta},\left\{W_{h}^{\text {ols }}\left(1+D_{i h} \widehat{\delta}\right)\right\}_{h=1}^{H}, b^{\text {ols }}\left(1+D_{i h} \widehat{\delta}\right)\right)
$$

\section{Appendix B: the Incidental Parameter Problem}

The least square estimators outlined above are subjected to a so-called "incidental parameter" problem. As firstly noticed by Neyman and Scott (1948), standard estimators of nonlinear panel data model are usually inconsistent if the length of the panel is small relative to the number of observations. In this 
case, the finite sample bias in the fixed effects parameters $\left(\left\{W_{h}\right\}_{h=1}^{H}\right.$ in our context) will not go away which contaminates the estimation in other parameters $(\delta$ and $b$ in $(18))$.

Given the partial nonlinearity in our model, an alternative approach that can get around with the incidental parameter problem is quasi-differencing. To see this, divide $K_{i h}$ on both sides of (17),

$$
\frac{y_{i h}}{K_{i h}}=W_{h}+\frac{X_{i h}}{K_{i h}} b+\frac{\varepsilon_{i h}}{K_{i h}}
$$

and then take the sibling difference within the same household

$$
\Delta \frac{y}{K}_{h}=\Delta \frac{X}{K}_{h} b+v_{h}
$$

where $\Delta \frac{x}{K}{ }_{h}=\frac{x_{1 h}}{K_{1 h}}-\frac{x_{2 h}}{K_{2 h}}$ and $v_{h}=\frac{\varepsilon_{1 h}}{K_{1 h}}-\frac{\varepsilon_{2 h}}{K_{2 h}}$. Notice that the household fixed effects have been eliminated in (23). The parameters left are $(\delta, b)$, which can be consistently estimated through NLS. $^{25}$

To decide which of these two approaches can deliver more accurate results, we conduct Monte Carlo experiments: pick up a set of "true" parameters' value, stimulate a data to mimic patterns of the real data, and then use the simulated data to estimate the parameters with our least square approach and the quasidifferencing method.

In each simulation, there are 126 households. Each of them is endowed with a $k_{0} w_{h}$ assuming to be log normal distributed. Its distribution parameters are chosen to mimic the moments of the household fixed effects $\left\{W_{h}\right\}_{h=1}^{H}$ we obtained from the data. Each household has one "first son". We randomly generate another two children's attributes, "indicator of the taller son" ( $\left.D_{i h}^{\text {taller }}\right)$ and "indicator of living with parents post marriage" $\left(D_{i h}^{\text {livep }}\right)$, such that their variance covariance matrix with the first son indicator $\left(D_{i h}^{1 s t s o n}\right)$ mimics the real data. We regress schooling expenditure on $k_{0} w_{h}$ and children's attributes using the actual dataset. Then collect the coefficients and the distribution parameters of the error terms and use them to generate the schooling investments for our simulated data. Note that the error terms here act as the ability endowments of the children. The inver-vivos transfer as simulated using equation (8) with the error terms being picked up to match the sample moments of the $t_{i h}$. The resulting data set is $\left\{s_{i h}, t_{i h}, D_{i h}^{\text {taller }}, D_{i h}^{\text {livep }}, D_{i h}^{1 \text { stson }}\right\}$ and we estimate the model

$$
t_{i h}=\left(1+\delta_{1} D_{i h}^{\text {taller }}+\delta_{2} D_{i h}^{\text {livep }}+\delta_{3} D_{i h}^{1 \text { stson }}\right) \cdot W_{h}+\beta s_{i h}+\varepsilon_{i h}
$$

with the "true" parameters as $\left(\beta, \delta_{1}, \delta_{2}, \delta_{3}\right)=(-0.3,0.2,0.4,-0.2)$. Note that we allow $\operatorname{cov}\left(s_{i h}, W_{h}\right)>0$ and $\operatorname{cov}\left(s_{i h}, D_{i h}\right)>0$, but keep $\operatorname{cov}\left(s_{i h}, \varepsilon_{i h}\right)=0$, which are the basic identification assumptions maintained in our paper.

Table A4 reports the results with 500 simulations. Panel A contains our least square results and panel B contains the quasi-differencing results. The

\footnotetext{
${ }^{25}$ For consistency we need $\operatorname{cov}\left(\Delta \frac{X}{K}{ }_{h}, v_{h}\right)=0$ in (23). This condition is ensured under our assumptions in the model.
} 
coefficients are the mean value of the 500 simulated estimates. In the brackets are their corresponding standard errors $(* * *$ Not the mean of the estimated standard errors $* * *)$. We are testing the $H_{0}$ as "mean of the estimates has the same value as the true parameters". ** means that the null can be rejected at 5 percent significance level.

With different specifications, the least square approach used in our paper delivers very precise estimates of the parameters. By contrast, the quasidifferencing results exhibit larger bias and standard errors, especially when all of the 3 attributes are controlled simultaneously. We conclude that, even though our least square estimates may be theoretically inconsistent, but its finite sample bias is negligible and its precision level is superior to the consistent quasi-differencing approach. ${ }^{26}$ We therefore based our conclusions on the least squared results.

\section{Appendix C: Proof of Proposition 5}

When schooling of the children have positive externality to parents' welfare, the optimization problem becomes

$$
\begin{aligned}
& \max U_{h}=\left(c_{h}+f_{1 h} r s_{1 h}+f_{2 h} r s_{2 h}\right)^{1-k_{1 h}-k_{2 h}} c_{1 h}^{k_{1 h}} c_{2 h}^{k_{2 h}} \\
& \text { s.t. } c_{i h}=r s_{i h}+t_{i h} \text { and } c_{h}+\sum_{i=1}^{2}\left(t_{i h}+C\left(s_{i h}\right)\right)=m_{h}
\end{aligned}
$$

Substituting for $t_{i h}$ in and rearrange the budget constraint yields:

$$
c_{p}+c_{1 h}+c_{2 h}=m_{h}+\sum_{i=1}^{2}\left(\left(1+f_{i h}\right) r s_{i h}-C\left(s_{i h}\right)\right) \equiv w_{h}
$$

where $c_{p} \equiv c_{h}+f_{1 h} r s_{1 h}+f_{2 h} r s_{2 h}$. Note that, for wealth maximization, the optimal schooling investments are higher than our baseline model, since the marginal return of schooling to the whole family is higher:

$$
\left(1+f_{i h}\right) r=M C\left(s_{i h}\right)
$$

Denote this schooling investments level as $s_{i h}^{\prime}$. Now the whole family's wealth is different with the baseline model as well:

$$
w_{h}^{\prime}=m_{h}+\sum_{i=1}^{2}\left(\left(1+f_{i}\right) r s_{i h}^{\prime}-C\left(s_{i h}^{\prime}\right)\right)
$$

\footnotetext{
${ }^{26}$ This conclusion has the same spirit with Greene (2004), who find that, through Monte Carlo methods, the coefficients in the Tobit model with fixed effect are "unaffected" by the incidental parameter problem. He notices that the estimators' behavior in models with a continuous dependent variable (whether truncated or not) is quite different with the binary choice models.
} 
Children's consumption levels are still proportional to the whole family wealth:

$$
\begin{aligned}
& c_{1 h}=k_{1 h} w_{h}^{\prime} \\
& c_{2 h}=k_{2 h} w_{h}^{\prime}
\end{aligned}
$$

Optimal transfers are determined by

$$
\begin{aligned}
& t_{1 h}=k_{1 h} w_{h}^{\prime}-r s_{1 h}^{\prime} \\
& t_{2 h}=k_{2 h} w_{h}^{\prime}-r s_{2 h}^{\prime}
\end{aligned}
$$


Table 1. Variable Definitions and Summary Statistics

\begin{tabular}{|c|c|c|c|c|c|c|c|}
\hline Variable Name & Unit & Definition or Notes & Obs & Mean & Std & Std w/i HH & $\begin{array}{c}\text { \# of } \mathrm{HH} \mathrm{w} / \\
\text { intra-HH } \\
\text { variations } \\
\end{array}$ \\
\hline \multicolumn{8}{|l|}{ Key Variables } \\
\hline yr_sch & year & Years of schooling. & 264 & 8.42 & $(2.90)$ & $(1.62)$ & 127 \\
\hline edu_exp & yuan $^{1}$ & Total educational expenditure. & 264 & 1555.93 & $(2784.61)$ & $(1916.87)$ & 127 \\
\hline mar_trans & yuan & Total monetory value of bride-price, including house, items and cash. & 264 & 5084.96 & $(5151.35)$ & $(2468.90)$ & 127 \\
\hline \multicolumn{8}{|l|}{ Sons' Attributes } \\
\hline age & & Age. & 264 & 33.87 & $(5.68)$ & $(2.83)$ & 127 \\
\hline age_mar & & Age at marriage. & 264 & 23.34 & $(2.53)$ & $(1.64)$ & 105 \\
\hline height & $\mathrm{cm}$ & Height. & 264 & 170.34 & $(5.80)$ & $(2.82)$ & 99 \\
\hline ag_expr & year & Agricultural experience before marriage. & 264 & 3.60 & $(4.60)$ & $(2.26)$ & 72 \\
\hline nonag_expr & year & Non-agricultural experience before marriage. & 264 & 2.91 & $(3.04)$ & $(1.60)$ & 88 \\
\hline live_in_pre & & Indicator of living with parents before marriage & 264 & 0.37 & $(0.48)$ & $(0.28)$ & 40 \\
\hline live_in_post & & Indicator of living with parents afrer marriage & 264 & 0.38 & $(0.49)$ & $(0.30)$ & 46 \\
\hline 1st_son & & Indicator of the first born son. & 264 & 0.48 & $(0.50)$ & $(0.50)$ & 126 \\
\hline \multicolumn{8}{|c|}{ Parental Attributes } \\
\hline yr_sch_fa & year & Father's years of schooling. & 127 & 5.32 & $(3.11)$ & & \\
\hline yr_sch_mo & year & Mother's years of schooling. & 127 & 3.06 & $(2.77)$ & & \\
\hline literacy_fa & & Indicator of father being literate. & 127 & 0.64 & $(0.48)$ & & \\
\hline literacy_mo & & Indicator of mother being literate. & 127 & 0.31 & $(0.47)$ & & \\
\hline n_sons & & Total number of sons in the household. & 127 & 2.42 & $(0.76)$ & & \\
\hline n_daughters & & Total number of daughters in the household. & 127 & 0.76 & $(0.82)$ & & \\
\hline \multicolumn{8}{|c|}{ Wealth Measures } \\
\hline ttl_house & yuan & Total value of houses ever built by the parents. & 127 & 11952 & $(12542)$ & & \\
\hline avg_house & yuan & Average value of houses ever built by the parents. & 127 & 4846 & $(5314)$ & & \\
\hline ttl_ag_equip & yuan & Total value of agricultural equipment ever possessed by the parents. & 127 & 2224 & $(5085)$ & & \\
\hline \multicolumn{8}{|l|}{ Residence } \\
\hline fengrun & & Indicator of residents in Fengrun county. & 127 & 0.35 & $(0.48)$ & & \\
\hline zhaoxian & & Indicator of residents in Zhaoxian county. & 127 & 0.29 & $(0.45)$ & & \\
\hline chicheng & & Indicator of residents in Chicheng county. & 127 & 0.37 & $(0.48)$ & & \\
\hline
\end{tabular}

1. All monetary value is deflated to 1980 price level. 
Table 2. Multiplicative Specification

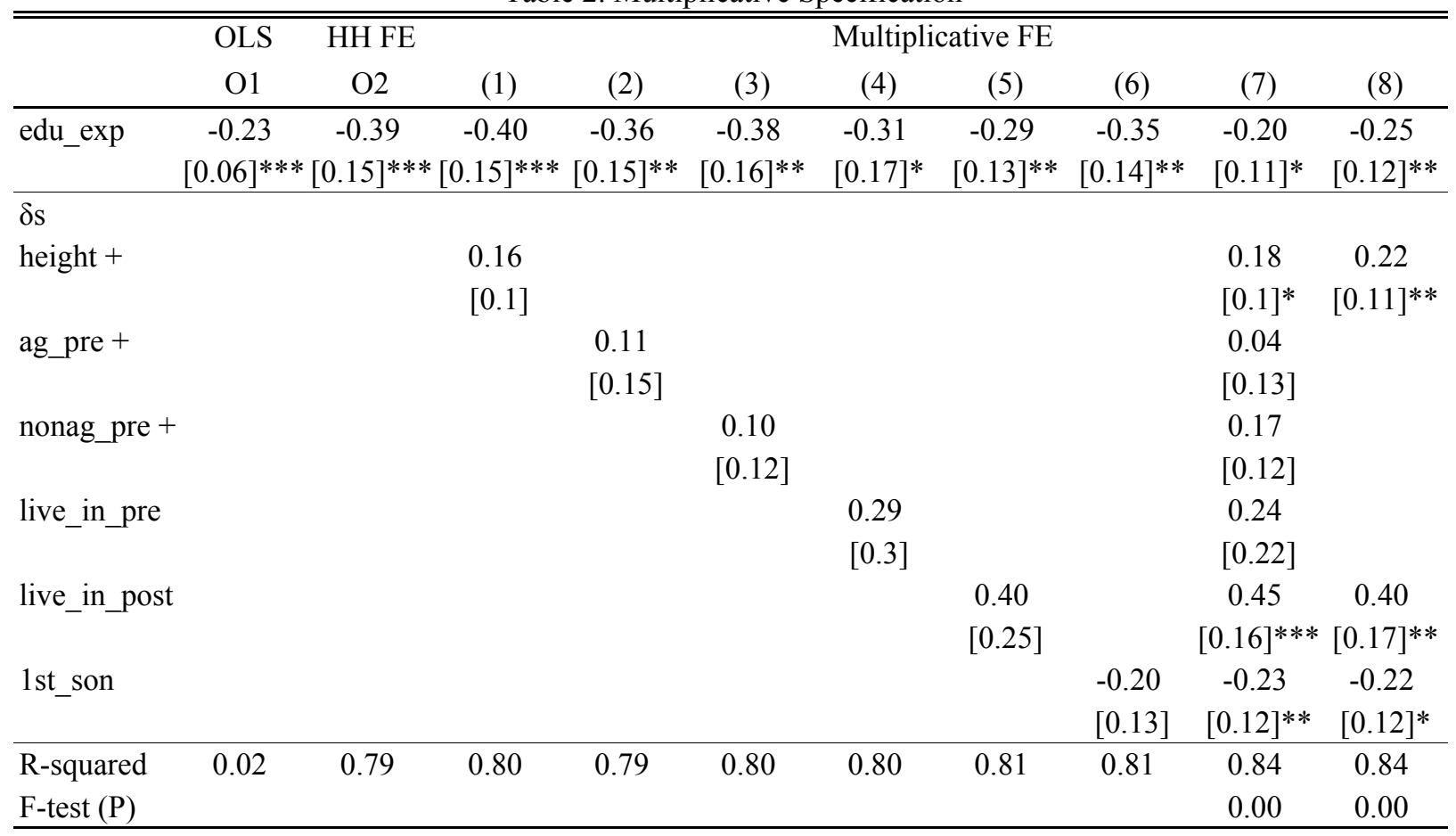

Note:

The last row reports the $\mathrm{p}$ value of the $\mathrm{F}$ test for the joint significance of kih. 
T3. Multiplicative Specification with Interaction Effects - exp dev

\begin{tabular}{|c|c|c|c|c|c|c|c|c|}
\hline & (1) & (2) & (3) & (4) & (5) & (6) & (7) & (8) \\
\hline edu_exp & $\begin{array}{c}-0.37 \\
{[0.19]^{*}}\end{array}$ & $\begin{array}{c}-0.36 \\
{[0.15]^{* *}}\end{array}$ & $\begin{array}{c}-0.33 \\
{[0.17]^{*}}\end{array}$ & $\begin{array}{c}-0.32 \\
{[0.13]^{* *}}\end{array}$ & $\begin{array}{c}-0.29 \\
{[0.12]^{* *}}\end{array}$ & $\begin{array}{l}-0.44 \\
{[0.28]}\end{array}$ & $\begin{array}{l}-0.18 \\
{[0.22]}\end{array}$ & $\begin{array}{l}-0.29 \\
{[0.2]}\end{array}$ \\
\hline \multicolumn{9}{|l|}{$\delta \mathrm{s}$} \\
\hline height + & $\begin{array}{c}0.17 \\
{[0.07]^{* *}}\end{array}$ & & & & & & $\begin{array}{c}0.22 \\
{[0.1]^{* *}}\end{array}$ & $\begin{array}{c}0.25 \\
{[0.08]^{* * *}}\end{array}$ \\
\hline exp_ag + & & $\begin{array}{c}0.10 \\
{[0.13]}\end{array}$ & & & & & $\begin{array}{c}0.17 \\
{[0.13]}\end{array}$ & \\
\hline exp_nonag - & & & $\begin{array}{c}0.16 \\
{[0.12]}\end{array}$ & & & & $\begin{array}{c}0.21 \\
{[0.17]}\end{array}$ & \\
\hline live_in_pre & & & & $\begin{array}{c}0.26 \\
{[0.15]^{*}}\end{array}$ & & & $\begin{array}{c}0.15 \\
{[0.22]}\end{array}$ & \\
\hline live_in_post & & & & & $\begin{array}{c}0.39 \\
{[0.17]^{* *}}\end{array}$ & & $\begin{array}{c}0.43 \\
{[0.21]^{* *}}\end{array}$ & $\begin{array}{c}0.40 \\
{[0.12]^{* * *}}\end{array}$ \\
\hline 1st_son & & & & & & $\begin{array}{c}-0.22 \\
{[0.1]^{* *}}\end{array}$ & $\begin{array}{c}-0.24 \\
{[0.12]^{* *}}\end{array}$ & $\begin{array}{c}-0.26 \\
{[0.08]^{* * *}}\end{array}$ \\
\hline \multicolumn{9}{|c|}{ Interaction w/ edu_exp } \\
\hline height + & $\begin{array}{l}-0.07 \\
{[0.24]}\end{array}$ & & & & & & $\begin{array}{l}-0.12 \\
{[0.16]}\end{array}$ & $\begin{array}{l}-0.16 \\
{[0.17]}\end{array}$ \\
\hline exp_ag + & & $\begin{array}{c}0.06 \\
{[0.87]}\end{array}$ & & & & & $\begin{array}{l}-0.63 \\
{[0.86]}\end{array}$ & \\
\hline exp_nonag - & & & $\begin{array}{l}-0.34 \\
{[0.25]}\end{array}$ & & & & $\begin{array}{l}-0.17 \\
{[0.24]}\end{array}$ & \\
\hline live_in_pre & & & & $\begin{array}{c}0.14 \\
{[0.48]}\end{array}$ & & & $\begin{array}{c}0.20 \\
{[0.34]}\end{array}$ & \\
\hline live_in_pos1 & & & & & $\begin{array}{c}0.10 \\
{[0.57]}\end{array}$ & & $\begin{array}{c}0.15 \\
{[0.59]}\end{array}$ & $\begin{array}{c}0.12 \\
{[0.51]}\end{array}$ \\
\hline 1st_son & & & & & & $\begin{array}{c}0.12 \\
{[0.28]} \\
\end{array}$ & $\begin{array}{c}0.05 \\
{[0.19]}\end{array}$ & $\begin{array}{c}0.14 \\
{[0.21]} \\
\end{array}$ \\
\hline R-squared & 0.80 & 0.79 & 0.80 & 0.80 & 0.81 & 0.81 & 0.84 & 0.84 \\
\hline F-test1 & & & & & & & 0.00 & 0.00 \\
\hline F-test2 & & & & & & & 0.90 & 0.71 \\
\hline
\end{tabular}

Notes:

The second last row reports the $\mathrm{p}$ value of the $\mathrm{F}$ test for the joint significance of kih.

The last row reports the $\mathrm{p}$ value of the $\mathrm{F}$ test for the joint significance of the interaction terms. 
T4. Multiplicative Specification with Discounting

\begin{tabular}{|c|c|c|c|c|c|c|c|c|c|}
\hline & \multicolumn{3}{|c|}{ Basic } & \multicolumn{3}{|c|}{ Preferred Specification } & \multicolumn{3}{|c|}{ "with Interactions } \\
\hline & $\mathrm{d}=0$ & $\mathrm{~d}=0.05$ & $\mathrm{~d}=0.1$ & $\mathrm{~d}=0$ & $\mathrm{~d}=0.05$ & $\mathrm{~d}=0.1$ & $\mathrm{~d}=0$ & $\mathrm{~d}=0.05$ & $\mathrm{~d}=0.1$ \\
\hline & (1) & (2) & (3) & (4) & (5) & (6) & (7) & (8) & (9) \\
\hline \multirow[t]{2}{*}{ edu_exp } & -0.40 & -0.26 & -0.14 & -0.25 & -0.21 & -0.16 & -0.29 & -0.16 & -0.06 \\
\hline & {$[0.15]^{* * *}$} & {$[0.12]^{* *}$} & {$[0.1]$} & {$[0.12]^{* *}$} & {$[0.1]^{* *}$} & {$[0.1]$} & {$[0.2]$} & {$[0.18]$} & {$[0.17]$} \\
\hline \multicolumn{10}{|l|}{$\delta \mathrm{s}$} \\
\hline \multirow[t]{2}{*}{ height +} & & & & 0.22 & 0.21 & 0.22 & 0.25 & 0.23 & 0.25 \\
\hline & & & & {$[0.11]^{* *}$} & {$[0.11]^{* *}$} & {$[0.11]^{*}$} & {$[0.08]^{* * *}$} & {$[0.07]^{* * *}$} & {$[0.07]^{* * *}$} \\
\hline \multirow{2}{*}{ live_in_post } & & & & 0.40 & 0.39 & 0.36 & 0.40 & 0.38 & 0.34 \\
\hline & & & & {$[0.17]^{* *}$} & {$[0.18]^{* *}$} & {$[0.18]^{* *}$} & {$[0.12]^{* * *}$} & {$[0.08]^{* * *}$} & {$[0.08]^{* * *}$} \\
\hline \multirow[t]{2}{*}{ 1st_son } & & & & -0.22 & 0.11 & 0.47 & -0.26 & 0.13 & 0.64 \\
\hline & & & & {$[0.12]^{*}$} & {$[0.11]$} & {$[0.12]^{* * *}$} & {$[0.08]^{* * *}$} & {$[0.07]^{*}$} & {$[0.07]^{* * *}$} \\
\hline \multicolumn{10}{|c|}{ Interaction w/ edu_exp } \\
\hline \multirow[t]{2}{*}{ height +} & & & & & & & -0.16 & -0.02 & 0.00 \\
\hline & & & & & & & {$[0.17]$} & {$[0.16]$} & {$[0.16]$} \\
\hline \multirow[t]{2}{*}{ live_in_pos } & & & & & & & 0.12 & 0.07 & 0.07 \\
\hline & & & & & & & {$[0.51]$} & {$[0.32]$} & {$[0.26]$} \\
\hline \multirow[t]{2}{*}{ 1st_son } & & & & & & & 0.14 & -0.04 & -0.17 \\
\hline & & & & & & & {$[0.21]$} & {$[0.18]$} & {$[0.15]$} \\
\hline R-squared & 0.80 & 0.82 & 0.80 & 0.84 & 0.83 & 0.84 & 0.84 & 0.83 & 0.84 \\
\hline F-test1 & & & & 0.00 & 0.00 & 0.00 & 0.00 & 0.01 & 0.00 \\
\hline F-test2 & & & & & & & 0.71 & 0.97 & 0.38 \\
\hline
\end{tabular}

Notes:

The second last row reports the $\mathrm{p}$ value of the $\mathrm{F}$ test for the joint significance of kih.

The last row reports the $\mathrm{p}$ value of the $\mathrm{F}$ test for the joint significance of the interaction terms. 


\section{T5. Instrument Educational Expedniture by Years of Schooling}

Panel A:

\begin{tabular}{|c|c|c|c|c|c|c|c|c|c|}
\hline & \multicolumn{3}{|c|}{ Basic } & \multicolumn{3}{|c|}{ Preferred Specification } & \multicolumn{3}{|c|}{ with Interactions } \\
\hline & $\mathrm{d}=0$ & $d=0.05$ & $\mathrm{~d}=0.1$ & $\mathrm{~d}=0$ & $\mathrm{~d}=0.05$ & $\mathrm{~d}=0.1$ & $\mathrm{~d}=0$ & $\mathrm{~d}=0.05$ & $\mathrm{~d}=0.1$ \\
\hline & $(1)$ & (2) & (3) & (4) & $(5)$ & $(6)$ & (7) & $(8)$ & $(9)$ \\
\hline \multirow[t]{2}{*}{ edu_exp } & -0.35 & -0.24 & -0.16 & -0.20 & -0.19 & -0.14 & -0.21 & -0.12 & -0.04 \\
\hline & {$[0.26]$} & {$[0.17]$} & {$[0.13]$} & {$[0.21]$} & {$[0.17]$} & {$[0.14]$} & {$[0.25]$} & {$[0.21]$} & [0.18] \\
\hline \multicolumn{10}{|l|}{$\delta \mathrm{s}$} \\
\hline \multirow[t]{2}{*}{ height +} & & & & 0.22 & 0.21 & 0.22 & 0.27 & 0.26 & 0.28 \\
\hline & & & & {$[0.11]^{* *}$} & {$[0.11]^{*}$} & {$[0.12]^{*}$} & {$[0.09]^{* * *}$} & {$[0.07]^{* * *}$} & {$[0.07]^{* * *}$} \\
\hline \multirow[t]{2}{*}{ live_in_post } & & & & 0.40 & 0.39 & 0.36 & 0.40 & 0.39 & 0.36 \\
\hline & & & & {$[0.18]^{* *}$} & {$[0.18]^{* *}$} & {$[0.19]^{*}$} & {$[0.13]^{* * *}$} & {$[0.1]^{* * *}$} & {$[0.09]^{* * *}$} \\
\hline \multirow[t]{2}{*}{ 1st_son } & & & & -0.22 & 0.11 & 0.47 & -0.28 & 0.09 & 0.64 \\
\hline & & & & {$[0.12]^{*}$} & {$[0.12]$} & {$[0.12]^{* * *}$} & {$[0.09]^{* * *}$} & {$[0.08]$} & {$[0.09]^{* * *}$} \\
\hline \multicolumn{10}{|c|}{ Interaction w/ edu_exp } \\
\hline \multirow[t]{2}{*}{ height +} & & & & & & & -0.24 & -0.11 & -0.07 \\
\hline & & & & & & & {$[0.22]$} & {$[0.18]$} & {$[0.16]$} \\
\hline \multirow[t]{2}{*}{ live_in_post } & & & & & & & 0.58 & 0.30 & 0.10 \\
\hline & & & & & & & {$[0.42]$} & {$[0.33]$} & {$[0.25]$} \\
\hline \multirow[t]{2}{*}{ 1st_son } & & & & & & & 0.19 & 0.00 & -0.17 \\
\hline & & & & & & & {$[0.22]$} & {$[0.19]$} & {$[0.19]$} \\
\hline R-squared & 0.78 & 0.81 & 0.82 & 0.83 & 0.83 & 0.83 & 0.84 & 0.83 & 0.84 \\
\hline F-test1 & & & & 0.00 & 0.00 & 0.00 & 0.00 & 0.02 & 0.00 \\
\hline F-test2 & & & & & & & 0.93 & 1.00 & 0.64 \\
\hline
\end{tabular}

Panel B: 1st Stage

\begin{tabular}{|c|c|c|c|c|c|c|c|c|c|}
\hline \multirow[t]{2}{*}{ yr_sch } & 769.24 & 883.35 & 1044.11 & 755.48 & 839.61 & 955.74 & 755.48 & 839.61 & 955.74 \\
\hline & {$[178.6]^{* *}$} & $232.84]^{*}$ & $307.54]^{* *}$ & {$[165.72]^{*}$} & $215.65]^{*}$ & $284.44]^{*}$ & {$[165.72]^{*}$} & $215.65]^{*}$ & $284.44]^{*}$ \\
\hline $\mathrm{R}$-squared & 0.73 & 0.72 & 0.71 & 0.76 & 0.74 & 0.73 & 0.76 & 0.74 & 0.73 \\
\hline
\end{tabular}

Panel C: Reduced Form

\begin{tabular}{|c|c|c|c|c|c|c|c|c|c|}
\hline & \multicolumn{3}{|c|}{ Basic } & \multicolumn{3}{|c|}{ Preferred Specification } & \multicolumn{3}{|c|}{ with Interactions } \\
\hline & $\mathrm{d}=0$ & $\mathrm{~d}=0.05$ & $\mathrm{~d}=0.1$ & $\mathrm{~d}=0$ & $\mathrm{~d}=0.05$ & $\mathrm{~d}=0.1$ & $\mathrm{~d}=0$ & $\mathrm{~d}=0.05$ & $\mathrm{~d}=0.1$ \\
\hline & (1) & (2) & (3) & (4) & $(5)$ & $(6)$ & (7) & $(8)$ & $(9)$ \\
\hline \multirow[t]{2}{*}{ yr_sch } & -208.52 & -183.42 & -153.10 & -63.02 & -126.16 & -95.79 & -149.26 & -104.26 & -75.70 \\
\hline & [206.33] & [151.01] & [138.97] & [137.37] & [147.66] & [131.88] & [176.26] & [144.88] & [130.6] \\
\hline R-squared & 0.78 & 0.81 & 0.82 & 0.83 & 0.82 & 0.83 & 0.83 & 0.83 & 0.84 \\
\hline
\end{tabular}

Notes:

The second last row reports the $p$ value of the $F$ test for the joint significance of kih.

The last row reports the $\mathrm{p}$ value of the $\mathrm{F}$ test for the joint significance of the interaction terms. 
T6. Adding Pre-mortem Bequests as Parts of the Transfers

Panel A. Summary Statistics of Pre-mortem Bequest

\begin{tabular}{cccc}
\hline \hline Items & $\begin{array}{c}\# \\
\text { Househo }\end{array}$ & $\begin{array}{c}\text { \# Household } \\
\text { making pre-mortem }\end{array}$ & $\begin{array}{c}\text { Mean Value }>0 \\
\text { (yuan) }\end{array}$ \\
\hline House & 127 & 94 & 4259 \\
Land & 127 & 83 & 2762 \\
Others & 127 & 12 & 2542 \\
\hline
\end{tabular}

Note:

1. Construction of land value measurement. Hebei Statistiscs Yearbook provides the net income from cultivation per mu in each year. We assume that half this income is the net return to human capital. Given the area of the land recieved by each son, the value of the land is defined as the sum of the total return to human capital over the 10 years since the land was given by the parents.

Panel B. Regression Results

\begin{tabular}{|c|c|c|c|c|c|c|c|c|c|}
\hline & \multicolumn{3}{|c|}{ Basic } & \multicolumn{3}{|c|}{ Preferred Specification } & \multicolumn{3}{|c|}{ with Interactions } \\
\hline & $\mathrm{d}=0$ & $\mathrm{~d}=0.05$ & $\mathrm{~d}=0.1$ & $\mathrm{~d}=0$ & $\mathrm{~d}=0.05$ & $\mathrm{~d}=0.1$ & $\mathrm{~d}=0$ & $\mathrm{~d}=0.05$ & $\mathrm{~d}=0.1$ \\
\hline \multirow[t]{2}{*}{ edu_exp } & -0.69 & -0.50 & -0.32 & -0.54 & -0.44 & -0.37 & -0.75 & -0.55 & -0.36 \\
\hline & {$[0.2]^{* * *}$} & {$[0.19]^{* * *}$} & {$[0.17]^{*}$} & {$[0.19]^{* * *}$} & {$[0.2]^{* *}$} & {$[0.2]^{*}$} & {$[0.18]^{* * *}$} & {$[0.17]$} & {$[0.17]$} \\
\hline \multicolumn{10}{|l|}{$\delta \mathrm{s}$} \\
\hline \multirow[t]{2}{*}{ height +} & & & & 0.02 & 0.02 & 0.04 & 0.02 & 0.04 & 0.10 \\
\hline & & & & {$[0.08]$} & {$[0.09]$} & {$[0.1]$} & {$[0.08]$} & {$[0.07]$} & {$[0.08]$} \\
\hline \multirow[t]{2}{*}{ live_in_post } & & & & 0.16 & 0.16 & 0.18 & 0.05 & 0.07 & 0.12 \\
\hline & & & & {$[0.14]$} & {$[0.16]$} & {$[0.18]$} & {$[0.11]$} & {$[0.09]$} & {$[0.09]$} \\
\hline \multirow[t]{2}{*}{ 1st_son } & & & & -0.19 & 0.01 & 0.25 & -0.23 & -0.05 & 0.23 \\
\hline & & & & {$[0.1]^{*}$} & {$[0.11]$} & {$[0.12]^{* *}$} & {$[0.08]^{* * *}$} & {$[0.08]$} & {$[0.09]^{* * *}$} \\
\hline \multicolumn{10}{|c|}{ Interaction w/ edu_exp } \\
\hline \multirow{2}{*}{ height +} & & & & & & & -0.01 & -0.11 & -0.18 \\
\hline & & & & & & & {$[0.3]$} & {$[0.26]$} & {$[0.26]$} \\
\hline \multirow[t]{2}{*}{ live_in_post } & & & & & & & 1.33 & 0.74 & 0.43 \\
\hline & & & & & & & {$[0.96]$} & {$[0.68]$} & [0.59] \\
\hline \multirow[t]{2}{*}{ 1st_son } & & & & & & & 0.28 & 0.17 & 0.02 \\
\hline & & & & & & & {$[0.29]$} & {$[0.27]$} & {$[0.23]$} \\
\hline R-squared & 0.84 & 0.87 & 0.87 & 0.87 & 0.87 & 0.87 & 0.87 & 0.87 & 0.88 \\
\hline F-test1 & & & & 0.00 & 0.39 & 0.00 & 0.01 & 0.86 & 0.32 \\
\hline F-test2 & & & & & & & 0.22 & 0.36 & 0.47 \\
\hline
\end{tabular}

Notes:

The second last row reports the $\mathrm{p}$ value of the $\mathrm{F}$ test for the joint significance of kih.

The last row reports the $\mathrm{p}$ value of the $\mathrm{F}$ test for the joint significance of the interaction terms. 
Table A1. Partial Appropriation of Schooling Returns by Sons

\begin{tabular}{lcc}
\hline \hline $\begin{array}{l}\text { Child's Attributes (relative to } \\
\text { his sibling when appicable) }\end{array}$ & $\begin{array}{c}\text { Proportion of tatol } \\
\text { educational return } \\
\text { appropriated by the son }\end{array}$ & $\begin{array}{c}\text { Sign of the interaction } \\
\text { effects with schooling } \\
\text { expenditure }\end{array}$ \\
\hline $\begin{array}{l}\text { Taller son } \\
\begin{array}{l}\text { More agiculture experience } \\
\text { before marriage }\end{array}\end{array}$ & less & $?$ \\
$\begin{array}{l}\text { More non-agiculture experience } \\
\text { before marriage }\end{array}$ & more & + \\
$\begin{array}{l}\text { Live outside the home before } \\
\text { marriage }\end{array}$ & more & - \\
$\begin{array}{l}\text { Live with the parents after } \\
\text { marriage }\end{array}$ & less \\
\begin{tabular}{l} 
First son \\
\hline
\end{tabular} & less & + \\
\hline
\end{tabular}


Table A2. Estimates of consumption level of the hypothetic son in each household (k0wh)

Panel A. Summary of k0wh from specifications in Table 2

\begin{tabular}{ccccc}
\hline \hline Spec & Obs & Mean & Std. Dev. & $\begin{array}{c}\text { Log-normality } \\
\text { Test }\end{array}$ \\
\hline$(1)$ & 127 & 5458 & 4360 & 0.21 \\
$(2)$ & 127 & 5574 & 4480 & 0.08 \\
$(3)$ & 127 & 5542 & 4402 & 0.16 \\
$(4)$ & 127 & 4833 & 3956 & 0.24 \\
$(5)$ & 127 & 4775 & 3818 & 0.26 \\
$(6)$ & 127 & 6303 & 5017 & 0.19 \\
$(7)$ & 127 & 3957 & 3294 & 0.19 \\
$(8)$ & 127 & 4787 & 3877 & 0.14 \\
\hline
\end{tabular}

Note: The "log-normality test" column reports the p-value of the

Kolmogorov-Smirnov distribution test with the null "the log of k0wh follows normal distribution”.

Panel C. Regression of k0wh on household level characteristics
Panel B. Distribution of k0wh.

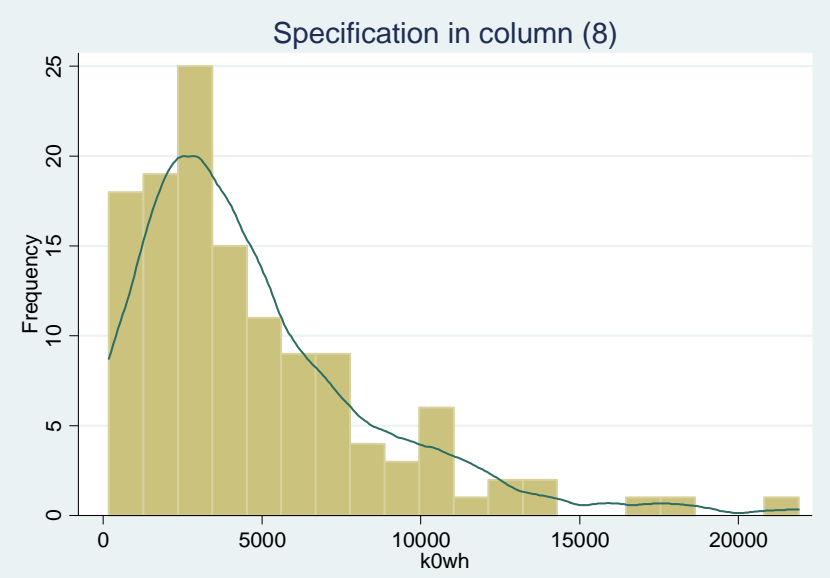

\begin{tabular}{lcccccccc}
\hline \hline \multirow{2}{*}{$\begin{array}{c}\text { Dep. Var.: } \\
\text { estmations of } \\
\text { k0wh }\end{array}$} & \multicolumn{7}{c}{ Specification in Table 2 used to estimate k0wh } \\
\cline { 2 - 9 } & $(1)$ & $(2)$ & $(3)$ & $(4)$ & $(5)$ & $(6)$ & $(7)$ & $(8)$ \\
\hline n_boy & -691.8 & -768.9 & -719.9 & -803.8 & -636.9 & -873.0 & -641.5 & -660.7 \\
& {$[331.1]^{* *}$} & {$[341.9]^{* *}$} & {$[340.2]^{* *}$} & {$[296.8]^{* * *}$} & {$[303.4]^{* *}$} & {$[386.6]^{* *}$} & {$[251.8]^{* *}$} & {$[306.8]^{* *}$} \\
n_girl & -617.2 & -696.1 & -617.4 & -645.3 & -523.3 & -671.9 & -399.8 & -450.0 \\
& {$[376.2]$} & {$[370.5]^{*}$} & {$[379.7]$} & {$[317.7]^{* *}$} & {$[300.9]^{*}$} & {$[437.0]$} & {$[249.9]$} & {$[307.7]$} \\
literacy_fa & 23.8 & 7.5 & 18.7 & -17.5 & 0.9 & 12.4 & -11.5 & 3.6 \\
& {$[92.6]$} & {$[94.3]$} & {$[93.5]$} & {$[86.3]$} & {$[80.5]$} & {$[108.1]$} & {$[69.7]$} & {$[81.1]$} \\
avg_house & 0.3 & 0.3 & 0.3 & 0.3 & 0.2 & 0.3 & 0.2 & 0.2 \\
& {$[0.1]^{* *}$} & {$[0.1]^{*}$} & {$[0.1]^{*}$} & {$[0.1]^{* *}$} & {$[0.1]^{*}$} & {$[0.2]^{*}$} & {$[0.1]^{*}$} & {$[0.1]^{*}$} \\
ttl_ag_equip & 0.3 & 0.3 & 0.2 & 0.2 & 0.2 & 0.3 & 0.2 & 0.3 \\
& {$[0.1]^{* * *}$} & {$[0.1]^{* * *}$} & {$[0.1]^{* * *}$} & {$[0.1]^{* * *}$} & {$[0.1]^{* * *}$} & {$[0.1]^{* * *}$} & {$[0.1]^{* * *}$} & {$[0.1]^{* * *}$} \\
fengrun & 415.3 & 501.0 & 467.5 & 407.5 & 534.6 & 655.9 & 474.3 & 567.2 \\
& {$[959.2]$} & {$[989.1]$} & {$[988.6]$} & {$[830.0]$} & {$[839.6]$} & {$[1,080.5]$} & {$[672.6]$} & {$[815.7]$} \\
chicheng & -1340.4 & -1379.8 & -1388.4 & -834.0 & -784.7 & -1501.6 & -541.3 & -795.7 \\
& {$[869.4]$} & {$[896.0]$} & {$[897.3]$} & {$[776.7]$} & {$[767.5]$} & {$[999.8]$} & {$[636.4]$} & {$[756.9]$} \\
\hline Obs & 127 & 127 & 127 & 127 & 127 & 127 & 127 & 127 \\
R-squared & 0.35 & 0.34 & 0.32 & 0.35 & 0.30 & 0.33 & 0.34 & 0.34 \\
\hline
\end{tabular}


TA3. Using Housholds with Land Division

\begin{tabular}{|c|c|c|c|c|c|c|c|c|c|}
\hline & $\mathrm{d}=0$ & $\mathrm{~d}=0.05$ & $\mathrm{~d}=0.1$ & $\mathrm{~d}=0$ & $\mathrm{~d}=0.05$ & $\mathrm{~d}=0.1$ & $\mathrm{~d}=0$ & $\mathrm{~d}=0.05$ & $\mathrm{~d}=0.1$ \\
\hline edu_exp & $\begin{array}{c}-0.43 \\
{[0.22]^{* *}}\end{array}$ & $\begin{array}{c}-0.37 \\
{[0.19]^{*}}\end{array}$ & $\begin{array}{l}-0.27 \\
{[0.16]}\end{array}$ & $\begin{array}{l}-0.27 \\
{[0.18]}\end{array}$ & $\begin{array}{l}-0.30 \\
{[0.19]}\end{array}$ & $\begin{array}{l}-0.29 \\
{[0.19]}\end{array}$ & $\begin{array}{c}-0.54 \\
{[0.25]^{* *}}\end{array}$ & $\begin{array}{c}-0.45 \\
{[0.2]^{* *}}\end{array}$ & $\begin{array}{l}-0.30 \\
{[0.19]}\end{array}$ \\
\hline \multicolumn{10}{|l|}{$\delta \mathrm{s}$} \\
\hline height + & & & & $\begin{array}{c}0.09 \\
{[0.12]}\end{array}$ & $\begin{array}{c}0.06 \\
{[0.11]}\end{array}$ & $\begin{array}{c}0.07 \\
{[0.11]}\end{array}$ & $\begin{array}{c}0.09 \\
{[0.09]}\end{array}$ & $\begin{array}{c}0.06 \\
{[0.08]}\end{array}$ & $\begin{array}{l}0.11 \\
{[0.1]}\end{array}$ \\
\hline live_in_post & & & & $\begin{array}{l}0.25 \\
{[0.2]}\end{array}$ & $\begin{array}{l}0.21 \\
{[0.2]}\end{array}$ & $\begin{array}{c}0.19 \\
{[0.19]}\end{array}$ & $\begin{array}{c}0.16 \\
{[0.1]^{*}}\end{array}$ & $\begin{array}{c}0.14 \\
{[0.09]}\end{array}$ & $\begin{array}{l}0.15 \\
{[0.1]}\end{array}$ \\
\hline 1st_son & & & & $\begin{array}{c}-0.31 \\
{[0.14]^{* *}}\end{array}$ & $\begin{array}{l}-0.04 \\
{[0.13]}\end{array}$ & $\begin{array}{c}0.25 \\
{[0.13]^{*}}\end{array}$ & $\begin{array}{c}-0.37 \\
{[0.09]^{* * *}}\end{array}$ & $\begin{array}{l}-0.11 \\
{[0.09]}\end{array}$ & $\begin{array}{c}0.23 \\
{[0.1]^{* *}}\end{array}$ \\
\hline \multicolumn{10}{|c|}{ Interaction w/ edu_exp } \\
\hline height + & & & & & & & $\begin{array}{l}-0.03 \\
{[0.29]}\end{array}$ & $\begin{array}{l}-0.04 \\
{[0.27]}\end{array}$ & $\begin{array}{l}-0.12 \\
{[0.26]}\end{array}$ \\
\hline live_in_pos1 & & & & & & & $\begin{array}{c}0.93 \\
{[0.77]}\end{array}$ & $\begin{array}{l}0.46 \\
{[0.6]}\end{array}$ & $\begin{array}{c}0.32 \\
{[0.55]}\end{array}$ \\
\hline 1st_son & & & & & & & $\begin{array}{l}0.37 \\
{[0.3]}\end{array}$ & $\begin{array}{c}0.21 \\
{[0.26]}\end{array}$ & $\begin{array}{c}0.03 \\
{[0.23]}\end{array}$ \\
\hline R-squared & 0.82 & 0.87 & 0.88 & 0.86 & 0.86 & 0.87 & 0.87 & 0.87 & 0.87 \\
\hline F-test1 & & & & 0.00 & 0.35 & 0.01 & 0.00 & 0.52 & 0.38 \\
\hline F-test2 & & & & & & & 0.19 & 0.50 & 0.64 \\
\hline
\end{tabular}


Table A4. Estimation Methods Comparison

Panel A. Least Square

\begin{tabular}{|c|c|c|c|c|c|}
\hline \multirow[b]{2}{*}{$\beta$} & \multicolumn{2}{|l|}{$\overline{\text { True Value }}$} & \multicolumn{2}{|c|}{ Estimation } & \multirow[b]{2}{*}{$\begin{array}{c}-0.30 \\
{[0.106]}\end{array}$} \\
\hline & -0.30 & $\begin{array}{c}-0.29 \\
{[0.099]}\end{array}$ & $\begin{array}{c}-0.30 \\
{[0.096]}\end{array}$ & $\begin{array}{c}-0.30 \\
{[0.104]}\end{array}$ & \\
\hline \multicolumn{6}{|l|}{$\delta \mathrm{s}$} \\
\hline height & 0.2 & $\begin{array}{c}0.20 \\
{[0.047]}\end{array}$ & & & $\begin{array}{c}0.20 \\
{[0.05]}\end{array}$ \\
\hline live_in_post & 0.4 & & $\begin{array}{c}0.40 \\
{[0.063]}\end{array}$ & & $\begin{array}{c}0.40 \\
{[0.076]}\end{array}$ \\
\hline 1st_son & -0.2 & & & $\begin{array}{c}-0.20 \\
{[0.034]}\end{array}$ & $\begin{array}{l}-0.20 \\
{[0.035]}\end{array}$ \\
\hline \multicolumn{6}{|c|}{ Note: $\mathrm{H0}$ : estimate=true value. } \\
\hline \multicolumn{6}{|c|}{ Panel B. Quasi-differencing } \\
\hline & True Value & & Estin & lation & \\
\hline beta & -0.30 & $\begin{array}{c}-0.28 \\
{[0.104]}\end{array}$ & $\begin{array}{c}-0.28 \\
{[0.103]}\end{array}$ & $\begin{array}{c}-0.31 \\
{[0.103]}\end{array}$ & $\begin{array}{c}-0.24 \\
{[0.158]}\end{array}$ \\
\hline height & 0.2 & $\begin{array}{c}0.27 \\
{[0.056]}\end{array}$ & & & $\begin{array}{c}0.39 \\
{[0.666]}\end{array}$ \\
\hline live_in_post & 0.4 & & $\begin{array}{c}0.51 \\
{[0.097]}\end{array}$ & & $\begin{array}{c}0.71 \\
{[0.911]}\end{array}$ \\
\hline 1st_son & -0.2 & & & $\begin{array}{c}-0.10 \\
{[0.046]^{* *}}\end{array}$ & $\begin{array}{l}-0.03 \\
{[0.349]}\end{array}$ \\
\hline
\end{tabular}

Note: $\mathrm{H} 0$ : estimate $=$ true value 
Table A5.1 Transfers Regression (level-level specifications)

Panel A: Without HH Fixed Effects

\begin{tabular}{|c|c|c|c|c|c|c|c|c|}
\hline & (1) & (2) & (3) & (4) & (5) & (6) & (7) & (8) \\
\hline \multirow[t]{2}{*}{ edu_exp } & -0.30 & -0.30 & -0.28 & -0.29 & -0.25 & -0.25 & -0.30 & -0.20 \\
\hline & {$[0.08]^{* * *}$} & {$[0.08]^{* * *}$} & {$[0.08]^{* * *}$} & {$[0.08]^{* * *}$} & {$[0.08]^{* * *}$} & {$[0.08]^{* * *}$} & {$[0.08]^{* * *}$} & {$[0.08]^{* *}$} \\
\hline \multirow[t]{2}{*}{ height +} & & 660.69 & & & & & & 622.92 \\
\hline & & [416.12] & & & & & & [410.47] \\
\hline \multirow[t]{2}{*}{ exp_ag +} & & & 404.93 & & & & & 186.45 \\
\hline & & & {$[553.03]$} & & & & & {$[564.47]$} \\
\hline \multirow[t]{2}{*}{ exp_nonag +} & & & & 378.79 & & & & 638.08 \\
\hline & & & & [474.69] & & & & {$[569.07]$} \\
\hline \multirow[t]{2}{*}{ live_in_pre } & & & & & 865.23 & & & 957.31 \\
\hline & & & & & [696.08] & & & [811.19] \\
\hline \multirow[t]{2}{*}{ live_in_post } & & & & & & 1498.27 & & 1412.04 \\
\hline & & & & & & {$[608.82]^{* *}$} & & {$[605.65]^{* *}$} \\
\hline \multirow[t]{2}{*}{ 1st_son } & & & & & & & 51.92 & 69.23 \\
\hline & & & & & & & [503.87] & [484.19] \\
\hline R-squared & 0.33 & 0.33 & 0.33 & 0.33 & 0.33 & 0.35 & 0.33 & 0.36 \\
\hline \multicolumn{9}{|c|}{ Panel B: With HH Fixed Effects } \\
\hline & (1) & $(2)$ & (3) & (4) & (5) & (6) & (7) & (8) \\
\hline \multirow[t]{2}{*}{ edu_exp } & -0.38 & -0.38 & -0.37 & -0.37 & -0.35 & -0.32 & -0.38 & -0.30 \\
\hline & {$[0.14]^{* *}$} & {$[0.14]^{* * *}$} & {$[0.14]^{* *}$} & {$[0.15]^{* *}$} & {$[0.16]^{* *}$} & {$[0.15]^{* *}$} & {$[0.15]^{* *}$} & {$[0.18]^{*}$} \\
\hline \multirow[t]{2}{*}{ height +} & & 491.72 & & & & & & 487.29 \\
\hline & & [527.63] & & & & & & [520.87] \\
\hline \multirow[t]{2}{*}{ exp_ag +} & & & 63.09 & & & & & -100.45 \\
\hline & & & [752.20] & & & & & [820.57] \\
\hline \multirow[t]{2}{*}{ exp_nonag + } & & & & 98.52 & & & & 238.68 \\
\hline & & & & [708.47] & & & & [781.78] \\
\hline \multirow[t]{2}{*}{ live_in_pre } & & & & & 517.71 & & & 503.12 \\
\hline & & & & & [972.00] & & & {$[1,029.51]$} \\
\hline \multirow[t]{2}{*}{ live_in_post } & & & & & & 1146.18 & & 1070.42 \\
\hline & & & & & & {$[1,143.19]$} & & {$[1,158.68]$} \\
\hline \multirow[t]{2}{*}{ 1st_son } & & & & & & & -184.32 & -228.35 \\
\hline & & & & & & & [846.33] & [842.42] \\
\hline R-squared & 0.80 & 0.80 & 0.80 & 0.80 & 0.80 & 0.81 & 0.80 & 0.81 \\
\hline
\end{tabular}


Table A5.2 Transfers Regression (log-log specifications)

Panel A: Without HH Fixed Effects

\begin{tabular}{|c|c|c|c|c|c|c|c|c|}
\hline & $(1)$ & $(2)$ & (3) & $(4)$ & $(5)$ & $(6)$ & $(7)$ & $(8)$ \\
\hline edu_exp & $\begin{array}{l}-0.05 \\
{[0.08]}\end{array}$ & $\begin{array}{l}-0.05 \\
{[0.08]}\end{array}$ & $\begin{array}{l}-0.03 \\
{[0.08]}\end{array}$ & $\begin{array}{l}-0.05 \\
{[0.08]}\end{array}$ & $\begin{array}{c}0.01 \\
{[0.08]}\end{array}$ & $\begin{array}{l}-0.02 \\
{[0.08]}\end{array}$ & $\begin{array}{l}-0.05 \\
{[0.08]}\end{array}$ & $\begin{array}{c}0.05 \\
{[0.08]}\end{array}$ \\
\hline height + & & $\begin{array}{c}0.07 \\
{[0.12]}\end{array}$ & & & & & & $\begin{array}{c}0.06 \\
{[0.13]}\end{array}$ \\
\hline exp_ag + & & & $\begin{array}{c}0.16 \\
{[0.16]}\end{array}$ & & & & & $\begin{array}{c}0.09 \\
{[0.16]}\end{array}$ \\
\hline exp_nonag + & & & & $\begin{array}{c}0.02 \\
{[0.13]}\end{array}$ & & & & $\begin{array}{c}0.14 \\
{[0.13]}\end{array}$ \\
\hline live_in_pre & & & & & $\begin{array}{c}0.40 \\
{[0.16]^{* *}}\end{array}$ & & & $\begin{array}{c}0.41 \\
{[0.16]^{* *}}\end{array}$ \\
\hline live_in_post & & & & & & $\begin{array}{c}0.44 \\
{[0.15]^{* * *}}\end{array}$ & & $\begin{array}{c}0.39 \\
{[0.15]^{* * *}}\end{array}$ \\
\hline 1st_son & & & & & & & $\begin{array}{c}0.07 \\
{[0.14]}\end{array}$ & $\begin{array}{c}0.09 \\
{[0.14]}\end{array}$ \\
\hline R-squared & 0.34 & 0.34 & 0.34 & 0.34 & 0.36 & 0.36 & 0.34 & 0.38 \\
\hline \multicolumn{9}{|c|}{ Panel B: With HH Fixed Effects } \\
\hline & $(1)$ & $(2)$ & $(3)$ & $(4)$ & $(5)$ & $(6)$ & $(7)$ & $(8)$ \\
\hline edu_exp & $\begin{array}{c}-0.30 \\
{[0.15]^{*}}\end{array}$ & $\begin{array}{c}-0.30 \\
{[0.16]^{*}}\end{array}$ & $\begin{array}{c}-0.31 \\
{[0.16]^{*}}\end{array}$ & $\begin{array}{c}-0.30 \\
{[0.15]^{* *}}\end{array}$ & $\begin{array}{c}-0.28 \\
{[0.16]^{*}}\end{array}$ & $\begin{array}{c}-0.27 \\
{[0.15]^{*}}\end{array}$ & $\begin{array}{c}-0.31 \\
{[0.16]^{*}}\end{array}$ & $\begin{array}{c}-0.28 \\
{[0.16]^{*}}\end{array}$ \\
\hline height + & & $\begin{array}{l}-0.02 \\
{[0.16]}\end{array}$ & & & & & & $\begin{array}{l}-0.02 \\
{[0.16]}\end{array}$ \\
\hline exp_ag + & & & $\begin{array}{l}-0.08 \\
{[0.24]}\end{array}$ & & & & & $\begin{array}{l}-0.09 \\
{[0.25]}\end{array}$ \\
\hline exp_nonag + & & & & $\begin{array}{l}-0.05 \\
{[0.18]}\end{array}$ & & & & $\begin{array}{l}-0.03 \\
{[0.20]}\end{array}$ \\
\hline live_in_pre & & & & & $\begin{array}{c}0.14 \\
{[0.29]}\end{array}$ & & & $\begin{array}{c}0.09 \\
{[0.32]}\end{array}$ \\
\hline live_in_post & & & & & & $\begin{array}{c}0.32 \\
{[0.27]}\end{array}$ & & $\begin{array}{c}0.30 \\
{[0.29]}\end{array}$ \\
\hline 1st_son & & & & & & & $\begin{array}{c}0.17 \\
{[0.28]}\end{array}$ & $\begin{array}{c}0.16 \\
{[0.29]}\end{array}$ \\
\hline R-squared & 0.75 & 0.75 & 0.75 & 0.75 & 0.75 & 0.76 & 0.75 & 0.76 \\
\hline
\end{tabular}


Tabke A6. Reduced Form Regression - Expenditure replaced by Years of Schooling

\begin{tabular}{|c|c|c|c|c|c|c|c|c|c|}
\hline & $\mathrm{d}=0$ & $\mathrm{~d}=0.05$ & $\mathrm{~d}=0.1$ & $\mathrm{~d}=0$ & $\mathrm{~d}=0.05$ & $\mathrm{~d}=0.1$ & $\mathrm{~d}=0$ & $\mathrm{~d}=0.05$ & $\mathrm{~d}=0.1$ \\
\hline yr_sch & $\begin{array}{l}-208.52 \\
{[206.33]}\end{array}$ & $\begin{array}{l}-183.42 \\
{[151.01]}\end{array}$ & $\begin{array}{l}-153.10 \\
{[138.97]}\end{array}$ & $\begin{array}{c}-63.02 \\
{[137.37]}\end{array}$ & $\begin{array}{l}-126.16 \\
{[147.66]}\end{array}$ & $\begin{array}{c}-95.79 \\
{[131.88]}\end{array}$ & $\begin{array}{l}-149.26 \\
{[176.26]}\end{array}$ & $\begin{array}{l}-104.26 \\
{[144.88]}\end{array}$ & $\begin{array}{l}-75.70 \\
{[130.6]}\end{array}$ \\
\hline \multicolumn{10}{|l|}{$\delta \mathrm{s}$} \\
\hline height + & $\begin{array}{l}0.16 \\
{[0.1]}\end{array}$ & $\begin{array}{c}0.10 \\
{[0.11]}\end{array}$ & $\begin{array}{c}0.07 \\
{[0.14]}\end{array}$ & $\begin{array}{c}0.22 \\
{[0.11]^{*}}\end{array}$ & $\begin{array}{c}0.21 \\
{[0.11]^{* *}}\end{array}$ & $\begin{array}{c}0.22 \\
{[0.12]^{*}}\end{array}$ & $\begin{array}{c}0.39 \\
{[0.12]^{* * *}}\end{array}$ & $\begin{array}{c}0.41 \\
{[0.1]^{* * *}}\end{array}$ & $\begin{array}{c}0.44 \\
{[0.1]^{* * *}}\end{array}$ \\
\hline live_in_post & & & & $\begin{array}{c}0.40 \\
{[0.17]^{* *}}\end{array}$ & $\begin{array}{c}0.39 \\
{[0.18]^{* *}}\end{array}$ & $\begin{array}{c}0.36 \\
{[0.18]^{* *}}\end{array}$ & $\begin{array}{c}0.61 \\
{[0.17]^{* * *}}\end{array}$ & $\begin{array}{c}0.56 \\
{[0.14]^{* * *}}\end{array}$ & $\begin{array}{c}0.44 \\
{[0.11]^{* * *}}\end{array}$ \\
\hline 1st_son & & & & $\begin{array}{c}-0.22 \\
{[0.12]^{*}}\end{array}$ & $\begin{array}{l}0.11 \\
{[0.11]}\end{array}$ & $\begin{array}{c}0.47 \\
{[0.13]^{* * *}}\end{array}$ & $\begin{array}{c}-0.39 \\
{[0.11]^{* * *}}\end{array}$ & $\begin{array}{l}0.04 \\
{[0.1]}\end{array}$ & $\begin{array}{c}0.65 \\
{[0.1]^{* * *}}\end{array}$ \\
\hline \multicolumn{10}{|c|}{ Interaction w/ edu_exp } \\
\hline height + & & & & & & & $\begin{array}{l}-180.63 \\
{[126.67]}\end{array}$ & $\begin{array}{c}-149.36 \\
{[92]}\end{array}$ & $\begin{array}{l}-141.89 \\
{[75.08]^{*}}\end{array}$ \\
\hline live_in_pos1 & & & & & & & $\begin{array}{l}-150.15 \\
{[160.45]}\end{array}$ & $\begin{array}{c}-66.82 \\
{[167.69]}\end{array}$ & $\begin{array}{c}13.56 \\
{[151.92]}\end{array}$ \\
\hline 1st_son & & & & & & & $\begin{array}{c}155.85 \\
{[115.46]}\end{array}$ & $\begin{array}{l}23.05 \\
{[88.46]}\end{array}$ & $\begin{array}{l}-111.22 \\
{[122.39]}\end{array}$ \\
\hline R-squared & 0.78 & 0.81 & 0.82 & 0.83 & 0.82 & 0.83 & 0.83 & 0.83 & 0.84 \\
\hline F-test1 & 0.17 & 0.01 & 0.00 & 0.00 & 0.00 & 0.00 & 0.00 & 0.01 & 0.00 \\
\hline F-test2 & & & & & & & 1.00 & 1.00 & 1.00 \\
\hline
\end{tabular}

